\title{
A Review on Electrical Characteristics of Nanofluid based Transformer Oil
}

\author{
Mihir A. Bhatt ${ }^{1 *}$ and Praghnesh J. Bhatt ${ }^{2}$ \\ 'Department of Electrical Engineering, Chandubhai S. Patel Institute of Technology, Changa - 388421, \\ Gujarat, India; mihirbhatt.ee@charusat.ac.in \\ 2Department of Electrical Engineering, Pandit Deendayal Petroleum University, Gandhinagar - 382007, \\ Gujarat, India; Praghnesh.Bhatt@sot.pdpu.ac.in
}

\begin{abstract}
Objectives: To review the electrical property of different nanofluids such as AC/DC and impulse breakdown strength, partial discharge inception characteristic, dielectric loss factor and electrical resistivity. Methods: Dispersion of nanoparticles to host fluid is carried out by single-step and two-step methods to enhance the basic properties of nanofluids such as electrical and thermal conductivity, dielectric constant, denseness and relaxation time constant. Single step method follows the dispersion of nano particles into host fluid directly. In two-step method, dry powders of nano particles are prepared in first stage, which is dispersed to host fluid through magnetic stirrer or ultrasonic methods in second stage. Findings: The nanofluid in transformers can enhance the dielectric strength by almost $15-20 \%$ compared to mineral oil. The performance of the nanofluids under heavy electrical stress depends upon the types, volume fraction, shape and size of the nanoparticles dispersed in host fluid. The investigations conducted over the mixture of nanoparticles and transformer oil concludes that the electrical performance of the carrier oil is highly influenced by dispersing the nanoparticles of different varieties, mass and shape. The dispersion of nanoparticles will change the mode of ionization, reduces the formation of the electrons responsible for the breakdown, and thus delay the breakdown time. Applications: The excellent heat transfer and electrical isolation characteristics are the prerequisite of insulating liquids used in power transformers. Because of superior electrical and cooling performance of nanofluid compared to mineral oil at high voltage levels, the dielectric world has recognized the nanofluid as a promising insulating substitute for transformers.
\end{abstract}

Keywords:Electrical Characteristics, Dielectric Strength, Nanofluid, Review, Transformer Oil, PDIV

\section{Introduction}

The EHV and UHV transmission networks are required for bulk power transfer over long distances as to cater ever increasing electrical demands. It has brought the new challenges to provide the insulation system for the different equipment coming across the transmission path from generation end to the consumer end. The level of switching surges for the forthcoming EHV and UHV transmission networks are predominantly high and therefore the high voltage equipment must operate reliably to deal with more volatile and dynamic operating conditions.
Power transformer, one of the most important electrical equipment in transmission network for providing reliable energy flow and shares the largest investments for an electric utility in project executions ${ }^{1}$. The prospective upshot of transformer miscarriage may react in unfavorable destruction of power system that in turn forces the system into collapse ${ }^{2}$. Henceforth, the operational consistency and lifespan of transformers principally depend on attributes and standard of nonconducting material used for heat transfer and electrical isolation purposes ${ }^{3}$.

One of the conceivable disputes with present-day liquid-solid insulation structure in power transformer

${ }^{*}$ Author for correspondence 
that confines the smallness in blueprint/design of a transformer is the conflicting permittivity between them. Since the low standards and attributes, the liquid dielectric was pressurizing more than the solids at ac and/or impulse voltages, which force transformer to be explosive in operation ${ }^{4}$. Aside from the crucial job like shielding solid dielectrics, arc extinguishing and cooling, liquid insulations can also diminish the acoustics in transformers ${ }^{5}$. As a result, the mineral oil's characteristics to survive with emerging demand of high voltage transmission networks are undeniably essential ${ }^{3}$.

At present time, the word nanofluid becomes eminent and well known that leads the challenges and opportunities to the analysts over the past decades. The names "nanofluids" and "Nano-liquids" are employed collaboratively to express transformer oil/nanoparticle combination for electrical isolation and chilling purposes ${ }^{3}$. Particles (single, multiple or hybrid) with nano scaled dimensions are scattered with small percentage figure in transformer oil will construct the nanofluid and was introduced by experimenters at the Argonne National Laboratory ${ }^{6}$.

Recently, many researchers have published the articles, which are based on thermal properties of nanofluids $\mathrm{s}^{-\underline{10}, \underline{43}}$. However, a very less attention has been given to examine the electrical characteristics of Nano liquids. Hence, an attempt is made in this paper to present the comprehensive review on electrical characteristics of nanoparticle based transformer oil.

\section{Types of Nanoparticles for Transformer Oil}

The mineral oil is commonly used for chilling and isolation purpose in transformers due to its excellent physical, chemical and dielectric characteristics, which is the utmost requirement for better performance and long life expectancy of transformers. The investigations reported so far in the literatures on the adoption of nanostructured materials in mineral oil have demonstrated the drastic improvement in its chemical, heat transfer and electrical isolation properties ${ }^{11}$.

To attain these attributes of nanofluids, most remarkable trouble is the choice of the nano-dimensioned particles. Varieties of nano scaled particles have been experimented so far ${ }^{12}-\underline{42}$ and they are labeled as per electrical conductivity and permittivity into three considerable classifications:
- Conducting Nanoparticles: $\mathrm{Fe}_{3} \mathrm{O}_{4}, \mathrm{Fe}_{2} \mathrm{O}_{3}, \mathrm{ZnO}, \mathrm{SiC}$

- Semiconducting Nanoparticles: $\mathrm{TiO}_{2}, \mathrm{CuO}, \mathrm{Cu}_{2} \mathrm{O}$, CdS

- Dielectric Nanoparticles: $\mathrm{Al}_{2} \mathrm{O}_{3}, \mathrm{SiO}_{2}, \mathrm{BN}$

Figures 1 and 2 show the host fluids and various hybrid nanoparticles used by researchers during investigations, respectively $\underline{43}$.

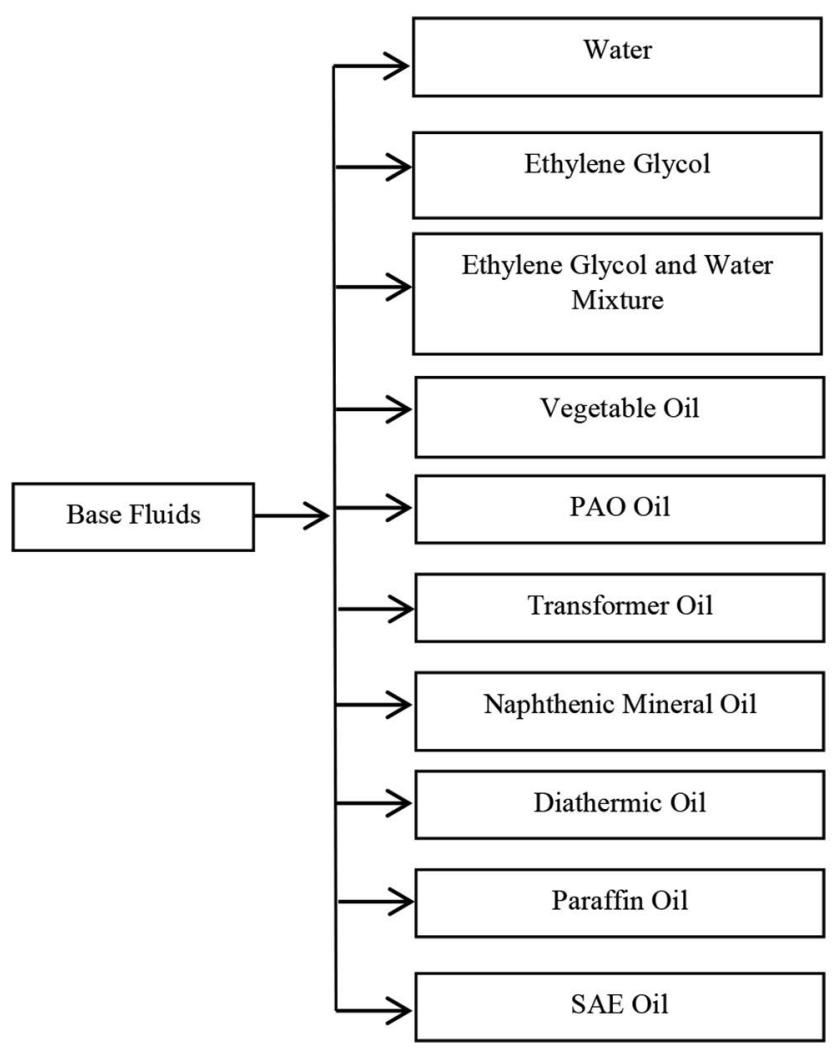

Figure 1. Host Fluids ${ }^{43}$.

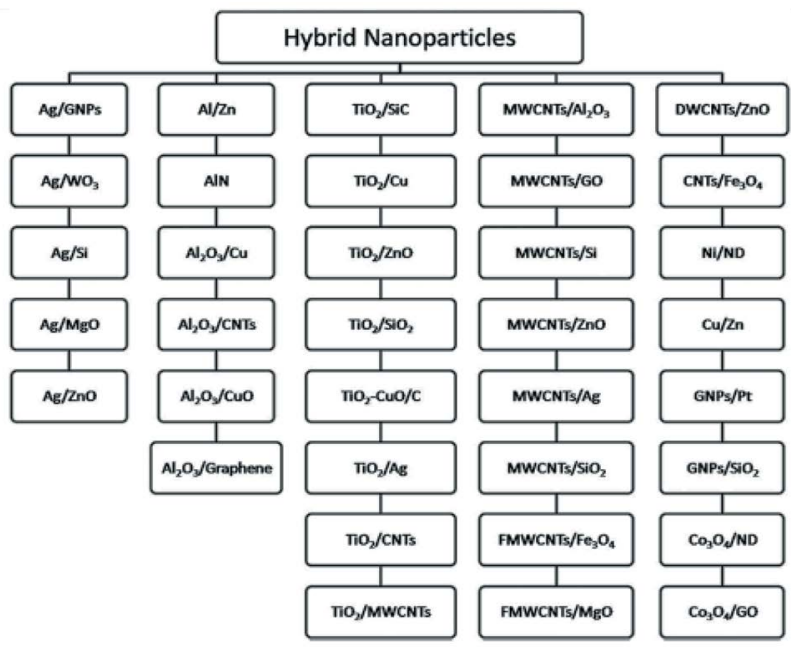

Figure 2. Hybrid Nano-composites ${ }^{43}$. 
The properties of a mineral oil based nanofluid developed after dispersion of either mono or hybrid nanoparticles widely be influenced by type, shape, size, constancy of dispersed nanoparticles, type of host fluid used and weight percentage of concentrated nanoparticles. Extensive research on nanofluid has shown the evidence of remarkable improvement in cooling performance than conventional fluid and preparation techniques for nanofluids is discussed in following section.

\section{Dispersion Techniques of Nanofluid}

The nanoparticles dispersed with an intention to enhance the insulation and cooling performance should keep the basic properties such as electrical and thermal conductivity, dielectric constant, denseness and relaxation time constant.

Out of these attributes, the rate of electron conduction and electron hindrance are the key properties to enhance electrical characteristic of nanoparticle based transformer oil. After the selection of an appropriate host fluid and nanoparticles as given in Figures 1 and 2, the crucial challenge encountered by the scholars is to take the appropriate method to devise the transformer oil based nanofluids. In general, the nanofluids can be formulated by using single step or 2-step methods as described.

Single-step Method: Inside single step approach, the nano scaled particles are disseminated conventionally into a host fluid to lessen the possibility of forming cluster with augmented stability ${ }^{3}, \underline{12}$. One of the potential issues with this approach is the origination of agglomeration during the bulk creation. The cluster formation of the nanoparticles can be prevented by evaporationcondensation method.

Two-step Method: This method is largely used for fabricating the nanofluids. In first stage of development, the particles of different shapes at nano range are firstly manufactured as dry powders via physical and chemical processes. In second stage, magnetic stirrer or ultrasonication achieves the steady dispersal of particles in host fluid. This method uses the distillation process for bulk creation of nanofluids that makes this mechanism of producing nanofluids high-priced. The basic flow of this method is shown in Figure 3. Table 1 outlines the methodologies adopted by different analysts to develop the nanofluids.

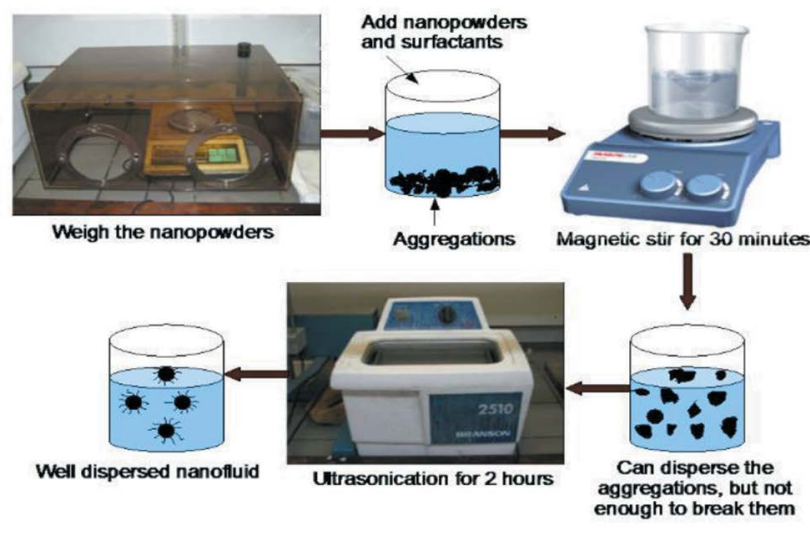

Figure 3. Two-step method for preparation ofnanofluid $\mathrm{d}^{44}$.

\section{Electrical Properties of Nanofluids}

The reliability and efficient performance of power/ distribution transformers are extremely biased by the physical, chemical and electrical properties of the dielectrics used within. The mineral oil is the most preferred coolant and insulator in the transformers as it possesses all these features. The nanofluids prepared for augmentation should demonstrate its excellent performance upon the application of high AC, DC and impulse voltages. In addition to that its characteristic behaviour should be evaluated for the partial discharge, electrical conduction nature and relative permittivity. This section comprehensively deliberates the insulation behavior of nanofluids considering the dimension/mass, nature and concentration of nanoparticles, moisture level and ageing.

\subsection{AC Dielectric Strength}

Supreme prerequisite for the liquid dielectric that governs the harmless operation of transformers, which are cooled by such liquids, is the dielectric strength. Generally, a numerous procedures suggested by the standards are employed to investigate the electrical stress withstanding capacity of the dielectric liquid by emphasizing them to nearly homogenous electric field. The magnitude of AC sparking potential deliberately specifies the grade of the oil.

The presence of the impurities and chemical agents dissolved for achieving superior properties significantly affects the liquid's dielectric strength. Hereafter, in present time, the researchers have started to investigate 
Table 1. Summary of single type and hybrid nanofluids and preparation methods adopted by researchers

\begin{tabular}{|c|c|c|c|c|}
\hline $\begin{array}{l}\text { Ref. } \\
\text { No. }\end{array}$ & Author (s) & Base Fluid & Type of NP & $\begin{array}{c}\text { Method of } \\
\text { Preparation }\end{array}$ \\
\hline 02 & Chiesa and Sarit & Transformer oil & $\mathrm{Al}_{2} \mathrm{O}_{3}, \mathrm{Fe}_{2} \mathrm{O}_{3}, \mathrm{SiC}, \mathrm{SiO}_{2}$ & Two step \\
\hline 13 & Lv et al. & Kelamayi\# transformer oil & $\mathrm{Al}_{2} \mathrm{O}_{3}, \mathrm{SiO}_{2}, \mathrm{TiO}_{2}$ & Two step \\
\hline 15 & Du et al. & Transformer oil & $\mathrm{BN}, \mathrm{Fe}_{3} \mathrm{O}_{4}$ & Two step \\
\hline 16 & Huifei et al. & Diala S3ZXIG mineral oil & Silica & Two step \\
\hline 19 & Eman et al. & Transformer oil & $\mathrm{TiO}_{2}$ & Two step \\
\hline 21 & Purbarun et al. & Transformer oil & Graphene, CNT & Two step \\
\hline 22 & Karthik et al. & Shell Diala D transformer oil & $\begin{array}{c}\text { Silicon Dioxide, Tin oxide, } \\
\text { magnetite }\end{array}$ & Two step \\
\hline 23 & Yuefan et al. & Kelamayi\# 25 transformer oil & $\mathrm{TiO}_{2}$ & Two step \\
\hline 27 & Wang et al. & Kelamayi mineral oil & $\mathrm{Al}_{2} \mathrm{O}_{3}, \mathrm{Fe}_{3} \mathrm{O}_{4}, \mathrm{TiO}_{2}$ & Two step \\
\hline 34 & John et al. & Paraffin oil & $\mathrm{Al}_{2} \mathrm{O}_{3}, \mathrm{TiO}_{2}, \mathrm{CuO}, \mathrm{Cu}_{2} \mathrm{O}$ and $\mathrm{Fe}_{2} \mathrm{O}_{3}$ & Two step \\
\hline 35 & Jian et al. & Vegetable oil & $\mathrm{Fe}_{3} \mathrm{O}_{4}$ & Two step \\
\hline 41 & Andrea et al. & Shell Diala D & $\begin{array}{l}\text { Magnetite, } \\
\text { GO, SO }\end{array}$ & Two step \\
\hline 42 & Jacek et al. & Ethylene glycol & $\mathrm{TiO}_{2}$ & Solid phase method \\
\hline 45 & Sadegh and Amin & Transformer oil & $\mathrm{WO}_{3}-\mathrm{Ag}$ & Single step \\
\hline 53 & Soo Hui et al. & Mineral oil & SiO2-Graphene & Two step \\
\hline 54 & Sandeepkumar et al. & Vegetable oil & $\mathrm{Cu}-\mathrm{Zn}$ & Two step \\
\hline 55 & Makmud et al. & Natural Ester & $\mathrm{Fe}_{2} \mathrm{O}_{3}, \mathrm{TiO}_{2}$ & Two step \\
\hline 56 & Chitra and Gayathri & Transformer oil & $\mathrm{Mg}_{0.40} \mathrm{Mn}_{0.60}-\mathrm{xNixFe} \mathrm{O}_{4}$ & - \\
\hline 57 & Diaa-Eldin et al. & $\begin{array}{c}\text { Shell diala S2 ZU-I Transformer } \\
\text { oil }\end{array}$ & $\mathrm{Al}_{2} \mathrm{O}_{3}, \mathrm{TiO}_{2}$ & Two step \\
\hline 58 & $\begin{array}{l}\text { Wittawat and } \\
\text { Amnart }\end{array}$ & Natural Ester & $\mathrm{ZnO}$ & Two step \\
\hline 60 & Georgios et al. & Natural Ester & MION & Two step \\
\hline
\end{tabular}

Table 2. Transformer-oil based Nanofluids

\begin{tabular}{|c|c|c|c|c|}
\hline $\begin{array}{c}\text { Nanoparticle/ } \\
\text { Oil }\end{array}$ & $\begin{array}{c}\text { Avg } \\
\text { Particle } \\
\text { size } \\
(\mathrm{nm})\end{array}$ & $\begin{array}{l}\text { Nanoparticle } \\
\text { Loading (\%) }\end{array}$ & $\begin{array}{c}\% \text { increase } \\
\text { in } \mathrm{BD} \\
\text { Strength }\end{array}$ & Ref. \\
\hline $\mathrm{TiO}_{2} / \mathrm{MO}$ & 20 & 0.6 & $13(\mathrm{AC})$ & 13 \\
\hline $\mathrm{Al}_{2} \mathrm{O}_{3} / \mathrm{MO}$ & 20 & 5 & $90.5(\mathrm{AC})$ & 13 \\
\hline $\mathrm{CuO} / \mathrm{MO}$ & 500 & 0.1 & $46.87(\mathrm{AC})$ & 14 \\
\hline \multirow{2}{*}{$\mathrm{Fe}_{3} \mathrm{O}_{4} / \mathrm{MO}$} & 20 & 0.1 & 120 (DC) & \multirow{2}{*}{15} \\
\hline & 20 & 0.1 & $100(\mathrm{AC})$ & \\
\hline \multirow{2}{*}{$\mathrm{BN} / \mathrm{MO}$} & 50 & 0.1 & 100 (DC) & \multirow{2}{*}{15} \\
\hline & 50 & 0.1 & $80(\mathrm{AC})$ & \\
\hline
\end{tabular}

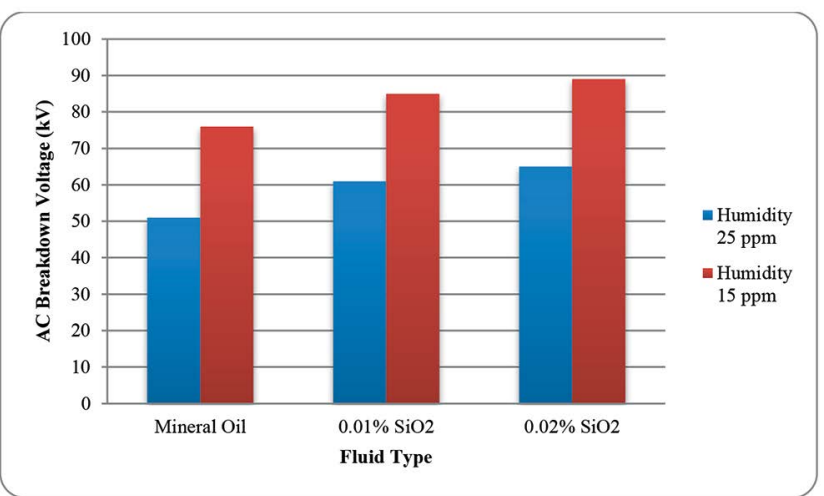

Figure 4. Dielectric strength of Mineral oil \& $\mathrm{SiO}_{2}$ based $\mathrm{NF}^{16}$. 
the liquids formulated by dispersing the nanoparticles with an intention to replace the existing mineral oil. The discussions over the electrical withstanding power of various nanofluids investigated by the scholars have been given in subsequent section. Table 2 shows the enhancement reported by different researchers in breakdown strength.

The dielectric strength of $\mathrm{SiO}_{2}$ based mineral oil under different ppm of moisture was investigated with different volume fraction of nanoparticles and the reported results are shown in Figure $4^{16}$. Due to hydrophilic nature, the surface of silicone dioxide can bind the water droplets effectively and thus reduces the effective electrical conduction in liquid. This will help in increasing the AC dielectric strength of prepared nanofluid by dispersing $\mathrm{SiO}_{2}$ NPs in mineral oil.

$\mathrm{In}^{17}$ have demonstrated the results of $\mathrm{AC} \mathrm{BDV}$ for transformer oil and magnetic fluid as a function of volume concentration at different ppm of water content. In Figure 5, remarkable improvement is observed in breakdown voltage with increasing the moisture level upto $0.2 \mathrm{~g} /$ lconcentration. The conductive nanoparticles act as electron scavengers, trap the electrons, turn into low mobility particles, and thus enhance the dielectric strength. On the other hand, it is shown that the dielectric strength is declined with upturn the percentage level of nanoparticles.

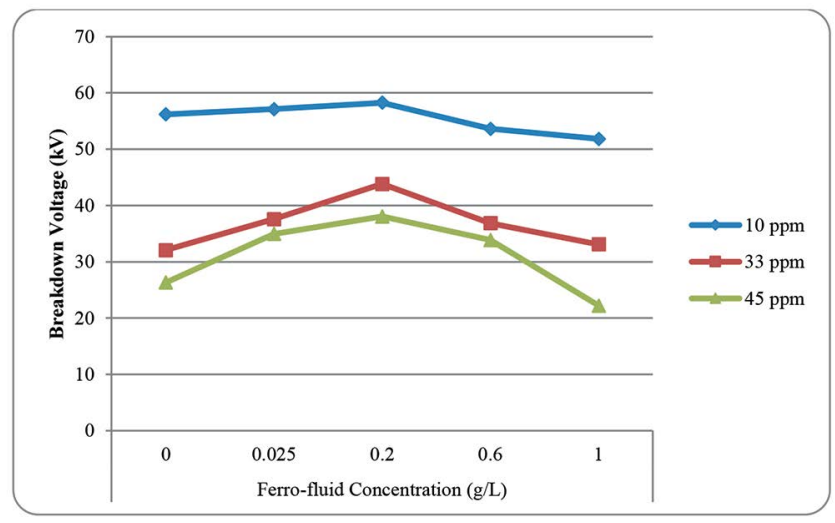

Figure 5. BDV mean values as a function of ferrofluid concentrations at $10 \mathrm{ppm}, 33 \mathrm{ppm}$ and $45 \mathrm{ppm}$ moisture level ${ }^{17}$.

$\operatorname{In}^{18}$ have executed investigation on transformer oil mixed with magnetic nanoparticle at volume concentrations of $0.08 \%$ to $0.45 \%$ to evaluate the behavior of breakdown voltage. Figure 6 shows Notable enhancement in dielectric strength of nanofluid at lower gap distance between two electrodes. The dispersed magnetic nanoparticles can act as electron scavengers to slow down the speed of massless electrons by transforming them into slow negatively charged atoms. On contrary, the dielectric strength is worsened when the distance is increased.

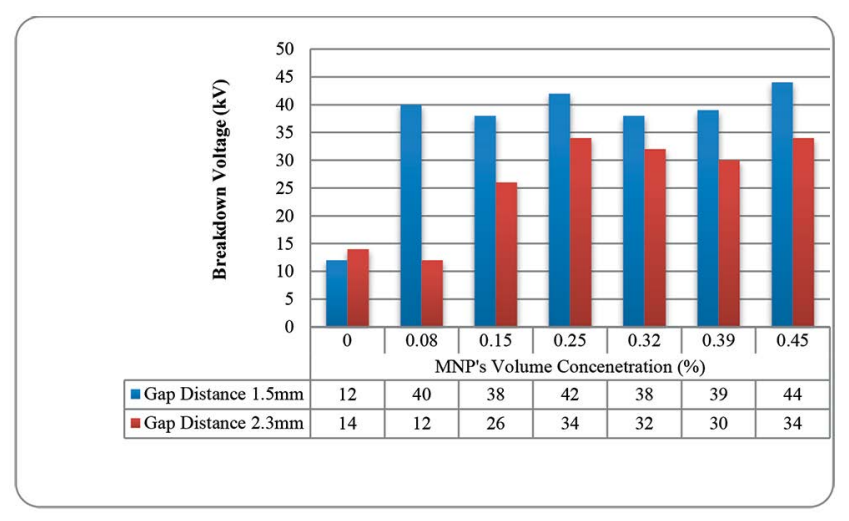

Figure 6. Breakdown voltage with different MNP's concentration ${ }^{18}$.

In $^{19}$ have prepared $\mathrm{TiO}_{2}$ based nanofluid using cationic surfactant Cetyl Trimethyl Ammonium Bromide (CTAB). They noticed the improvement in breakdown voltage because of the existence of suitable concentration of the surfactants which can effectively opposes the Van der Waals attraction force between the nanoparticles to stabilize them. Furthermore, the modified surface effectively influences on trapping and de-trapping process of electrons.

The effect of surface treatment on breakdown voltage of silica nanoparticles is examinedby ${ }^{20}$. The change observed is shown in Figure 7. As depicted in the figure, the enhancement has observed in dielectric strength when the mineral oil is prepared by dispersing the silicon dioxide nanoparticles with and without surface treatment. The discharged water droplets bound by the nanoparticles due to its hydrophilic nature-giving rise to high dielectric strength.

The Figure 8 shows the results reported by ${ }^{21}$ when the base liquid was modifying by dispersing the graphene nanoparticles and carbon nanotubes. The amelioration of the dielectric strength may occur due to: (1) the dispersed nanostructures alter the state of electrodynamics within the host oil and (2) the bigger values of the electrical conductivities reduce the charge relaxation time constant.

In $\underline{22}$ have examined the effect of aging on insulation strength of nanofluids prepared by dispersing conducting, 


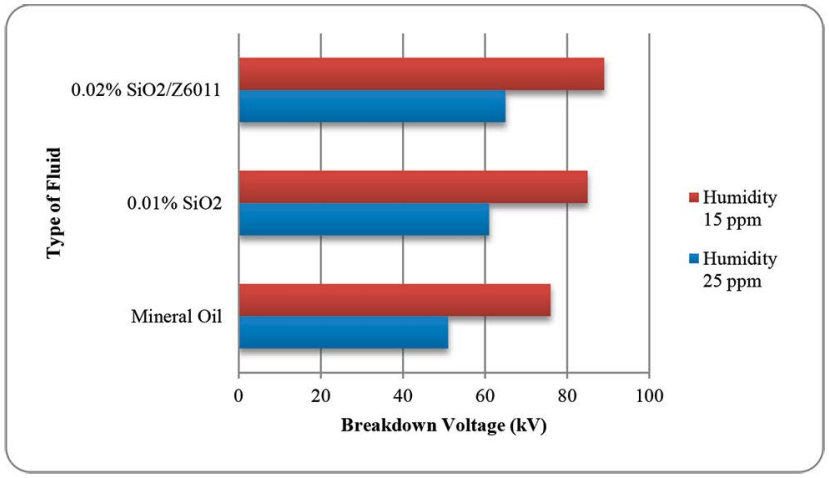

Figure 7. BDV for pure oil, modified and unmodified silica $\mathrm{NFs}^{20}$.

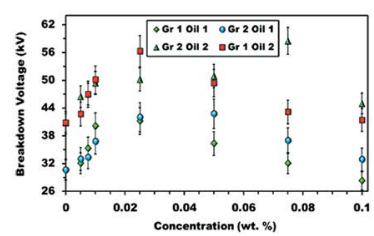

(a)

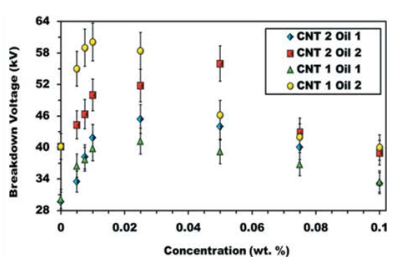

(b)
Figure 8. Sparking Potential of (a) Graphene \& (b) CNT based nano-oils ${ }^{21}$.

semi-conducting and non-conducting nanoparticles. Figure 9 reveals that the electrical strength of ferrofluid and pure oil declines because of aging albeit the electrical stability of non-conducting and semiconducting nanoparticles shows less dependency over the thermal aging.

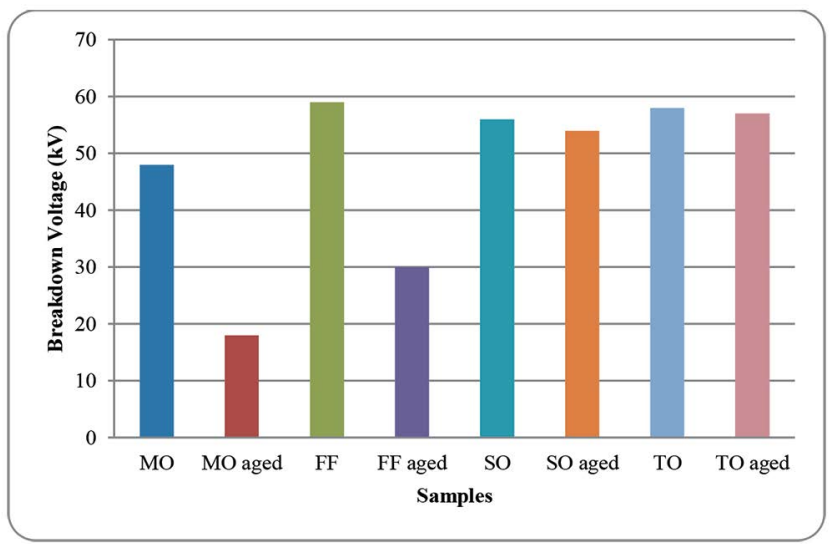

Figure 9. Sparking Potential of $\mathrm{MO}$ and various nanofluids ${ }^{22}$.

The influence of $\mathrm{Ag}-\mathrm{WO}_{3}$ based hybrid nanoparticles over the dielectric strength of transformer oil is investigated by ${ }^{45}$. They have prepared the hybrid nanofluid by one-step method and measured the constancy by zeta potential. The experiment shows little bit reduction in dielectric strength as compared to transformer oil due to higher electrical conductivity of silver nanoparticles and agglomeration occurs at high concentration.

In $\stackrel{46}{6}$ have examined the electrical isolation power of transformer oil based nanofluids containing silica and silver-coated silica with Newtonian flow behavior. The reduction observed in dielectric strength after dispersing the silica in transformer oil is due to moisture absorption nature of silica. Furthermore, the conductive nature of silver nanoparticles reduces the dielectric strength considerably when hybrid (silver supported silica) nanoparticles were dispersed in transformer oil.

In contrast, the dispersion of numerous nanoparticles can enhance the electrical strength of transformer oil to great extent under the high electrical field compared to the fluid developed by individual nanoparticles ${ }^{47}$. The amplification of electrical strength is achieved due to absorption offered by nanoparticles towards the free electrons when it is ionized by applied electrical field.

In $\stackrel{48}{~ h a v e ~ e x a m i n e d ~ t h e ~ i n f l u e n c e ~ o f ~ p l a s m a ~ t r e a t e d ~}$ and untreated $\mathrm{SiO}_{2}$ nanoparticle based nanofluid on insulation characteristic of transformer oil and shown in Figure 10. The dielectric strength can be improved by achieving the homogeneous dispersal and unwavering suspension of fine particles by applying plasma treatment on the nanofillers.

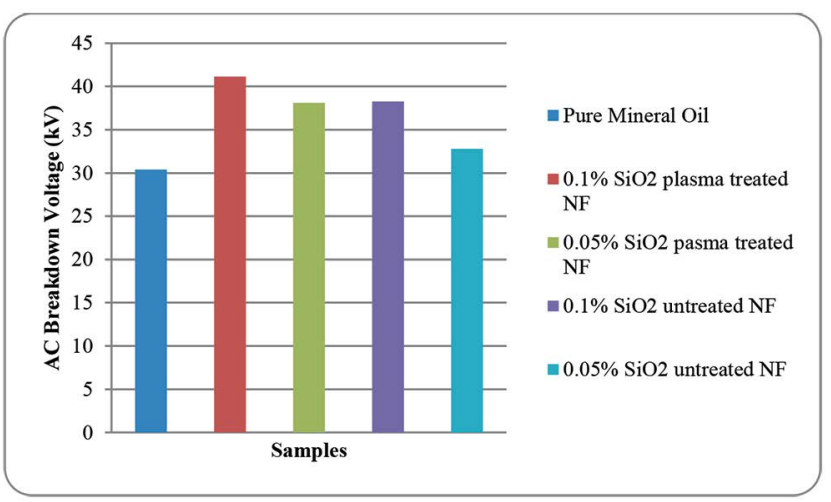

Figure 10. Comparison of $\mathrm{AC} \mathrm{BDV}$ for treated and untreated $\mathrm{NF}^{4}$.

In ${ }^{49}$ have achieved the enhancement of $2.2 \%$ in full discharge voltage when transformer oil is modified by dispersing graphene quantum dots. The reduction in effective electron mobility due to electron charging phenomena of nanoparticles that convert fast moving electrons to slow negatively charge carriers can enhance 
electrical stress withstanding capacity of transformer oil based nanofluid.

In $\stackrel{50}{ }$ have made the efforts to investigate the breakdown performance of $\mathrm{SiO}_{2}$ dispersed mineral oil based nanofluid. The dielectric strength shows the dependency over the volume fraction of nanoparticles. The reduction observed in breakdown voltage at higher concentration is explained by electric double layer (EDL) model.

In $\frac{51}{}$ inspected the insulating properties of botanical transformer oil with three different nanoparticles at different level of concentrations. They found the augmentation in breakdown voltage as $44 \%, 32 \%$ and $11 \%$ for $\mathrm{TiO}_{2}, \mathrm{ZnO}$ and $\mathrm{CuO}$ based nanofluids respectively. On contrary as shown in Figure 11, the dielectric strength of $\mathrm{CuO}$ based nanofluid is reduced dramatically as compared to others. The increase in size of $\mathrm{CuO}$ nanoparticles due to more aggregation reduces the surface to trap the electrons that harms the dielectric strength.

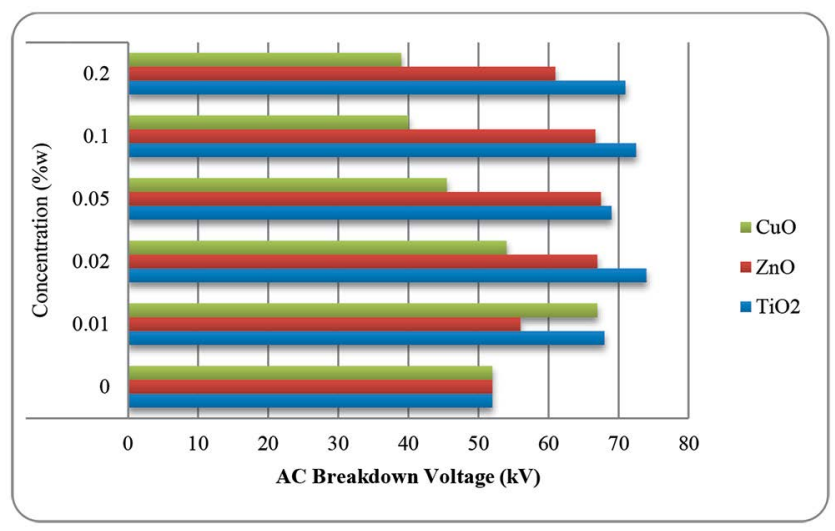

Figure 11. AC sparking potential at different mass fraction ${ }^{\underline{51}}$.

In ${ }^{52}$ have developed the vegetable oil based nanofluid by dispersing exfoliated hexagonal boron nitride (h-BN) and examined its AC breakdown voltage strength at $25^{\circ} \mathrm{C}$ and $90^{\circ} \mathrm{C}$ with gradual increase in volume fraction of nanoparticles. Figure 12 shows the influence of nanoparticle concentration on AC breakdown voltage.

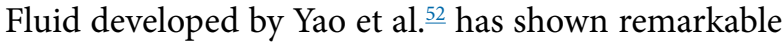
improvement in dielectric strength of base fluid at different temperature ranges with different concentrations of h-BN nanoparticles.

\subsection{Breakdown Strength}

The dielectric strength of $\mathrm{TiO}_{2}$ dispersed transformer oil under high voltage DC is examined by ${ }^{23}$. The addition of

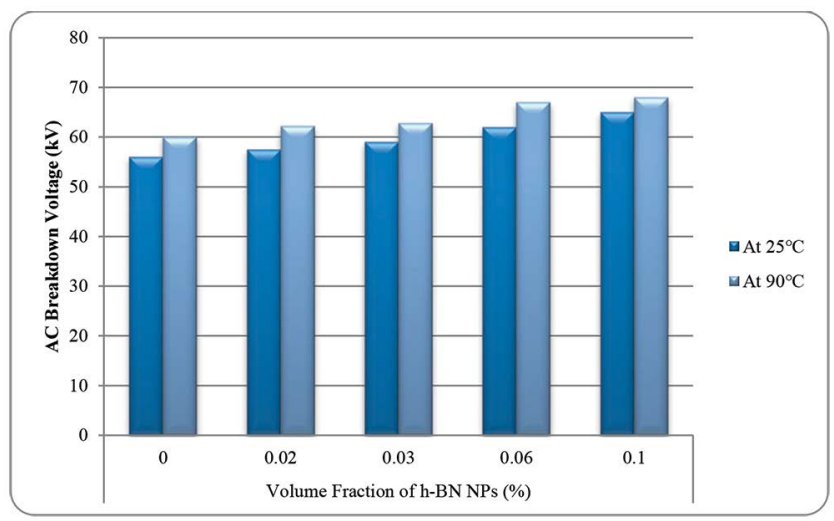

Figure 12. AC breakdown voltage strength with \%age volume fraction $\frac{52}{}$.

semiconductive nanoparticles can improve $28 \%$ value of negative DC breakdown strength. However, the positive DC breakdown voltage was lower than the host oil. Table 3 shows the obtained values during the investigations carried out by them ${ }^{23}$.

Table 3. DC discharge voltage of pure oil and nanofluid 23

\begin{tabular}{|c|c|c|}
\hline Samples & $\begin{array}{c}\text { (+) DC Breakdown } \\
\text { Voltage }(\mathrm{kV})\end{array}$ & $\begin{array}{c}\text { (-) DC Breakdown } \\
\text { Voltage }(\mathrm{kV})\end{array}$ \\
\hline Mineral Oil & 49.1 & 66.3 \\
\hline Nanofluid & 45.1 & 84.6 \\
\hline
\end{tabular}

In ${ }^{24}$ have observed that the dispersed semiconducting NPs can provide the augmentation to the insulation strength under DC voltage due to its trapping and de-trapping nature. The augmentation of $\mathrm{dc}$ dielectric strength of nanofluid was 1.27 times more than the host oil.

Figure 13 shows the results of investigation conducted by researchers for the influence of dispersing $\mathrm{Fe}_{3} \mathrm{O}_{4}$ nanoparticles as a function of gap length ${ }^{25}$. The formation of bubbles due to localized heating and the injection of field-emitted electrons with and without magnetic field can reduce DC breakdown voltage at $2 \%$ concentration.

Figure 14 represents the influence of nanoparticle's volume fraction on DC breakdown voltage strength of vegetable oil based nanofluid examined by ${ }^{52}$. Due to the polarization of the nanoparticles under applied DC field, the electrons produced by the ionization will trapped by the formulated electrical charge around the surface of NPs and thus helps in reducing the probability of ionization to prevent the breakdown. 


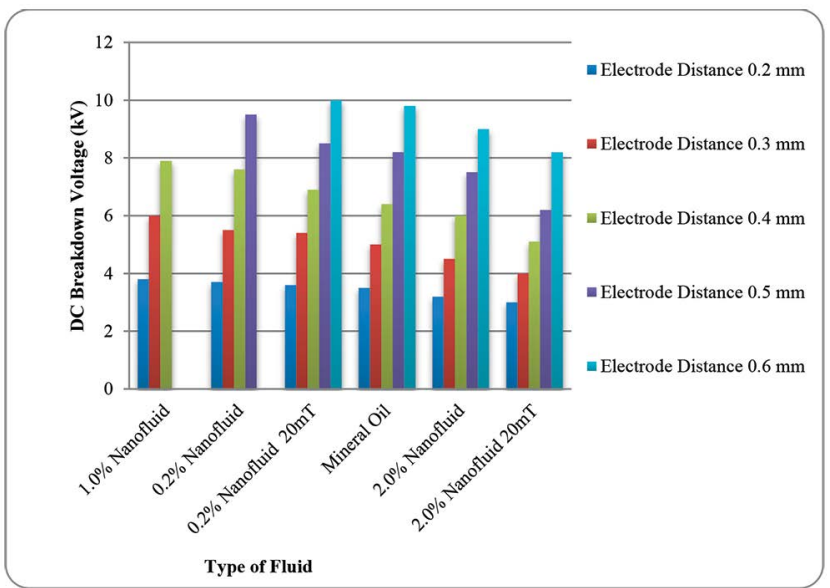

Figure 13. Dielectric strength with and without magnetic field of $20 \mathrm{mT}$ under DC stress $\stackrel{25}{ }$.

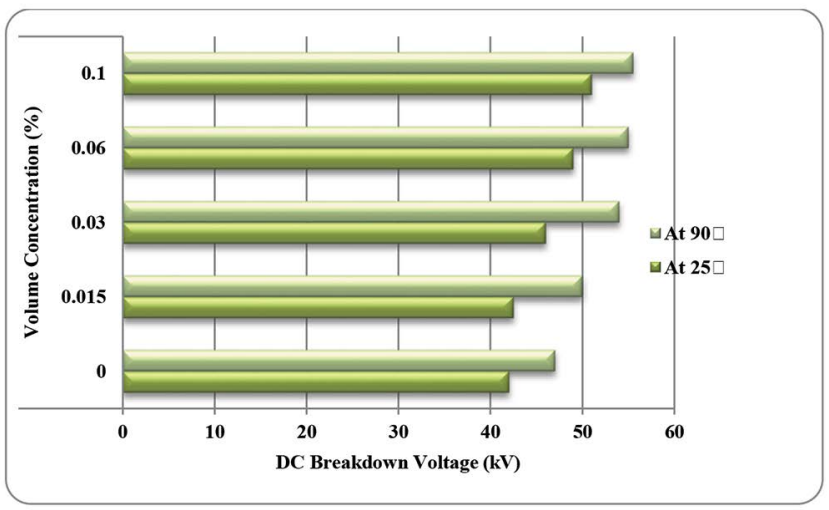

Figure 14. DC BDV as a function of \%ageabsorption ${ }^{52}$.

To investigate the DC dielectric strength ${ }^{59}$ have prepared the fluid by dispersing the single type and multiple type nanoparticles in transformer oil. They noticed that the breakdown strength is decreasing when the $\mathrm{Fe}_{2} \mathrm{NiO}_{4}$ nanoparticle is dispersed along with $\mathrm{CdS}$ in transformer oil. Increase in nanoparticles concentration would result in reducing the separation between two particles and increase the chance of agglomeration. These clusters lead to distort the electric field extensively and additionally reduce the electron trap surface.

In ${ }^{61}$ have inspected the DC strength of vegetable oil based nanofluid prepared by dispersing Boron Nitride (BN) nanoparticles at different volume size as a function of heat range. Figure 15 shows the results obtained by them.

The breakdown voltage is enhanced due to removal of moisture content from the liquid with rise in heat rate. The dispersion of BN nanoparticles at high concentration hinders the progression of dielectric breakdown.

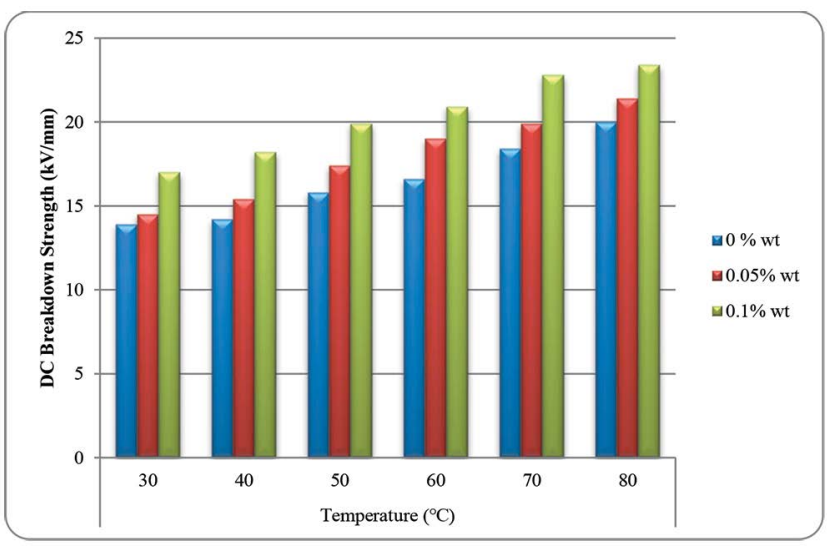

Figure 15. DC breakdown voltage $e^{61}$.

In $\underline{62}$ have made the efforts to check the DC strength of transformer oil by preparing the nanofluid by adding $\mathrm{Fe}_{3} \mathrm{O}_{4}$ and $\mathrm{BN}$ nanoparticles. The result verifies the better performance when nanofluid is prepared by $\mathrm{BN}$ nanoparticles as compared to $\mathrm{Fe}_{3} \mathrm{O}_{4}$ based nanofluid.

In $\underline{63}$ have conducted the DC breakdown voltage test as per D3755 standard on $\mathrm{TiO}_{2}$ transformer oil based nanofluid impregnated pressboard. The results show the remarkable improvement of $5.97 \%$ and $6.5 \%$ in positive and negative DC breakdown voltages respectively.

\subsection{Impulse Breakdown Strength}

Tables 4 and 5 shows the outcomes for failure of pure oil and $\mathrm{TiO}_{2}$ based nanofluid studied by applying impulse voltage with positive and negative polarity ${ }^{26}$.

Table 4. Positive breakdown strength of pure oil and $\mathrm{NF}^{26}$

\begin{tabular}{|c|c|c|}
\hline Samples & $\begin{array}{c}\text { Breakdown } \\
\text { Voltage }(\mathrm{kV})\end{array}$ & $\begin{array}{c}\text { Time to breakdown } \\
(\mu \mathrm{s})\end{array}$ \\
\hline Mineral Oil & 74.27 & 13.18 \\
\hline Nanofluid & 97.16 & 97.16 \\
\hline
\end{tabular}

Table 5. Negative breakdown strength of pure oil and $\mathrm{NF}^{2} \underline{26}$

\begin{tabular}{|c|c|c|}
\hline Samples & $\begin{array}{c}\text { Breakdown Voltage } \\
(\mathrm{kV})\end{array}$ & $\begin{array}{c}\text { Time to } \\
\text { breakdown }(\mu \mathrm{s})\end{array}$ \\
\hline Mineral Oil & -116.42 & 49.58 \\
\hline Nanofluid & -108.46 & 11.39 \\
\hline
\end{tabular}

The dispersion of semiconductive nanoparticles effectively changes the scattering of space charge caused 
by shallow traps and thus modifies the appearances of streamer transmission and interruption. At the head of streamer during positive polarity, the electrical field is distorted extensively due to induced negative charges that delay the propagation of streamer whereas it speeds up when negative impulse is applied.

Wang et al. ${ }^{27}$ deliberated the effect of three dissimilar nanoparticles on impulse breakdown strength at different concentrations. Figures 16 and 17 shows the result of failure at applied impulse voltage as a function of size percentage for three dissimilar nanoparticles.

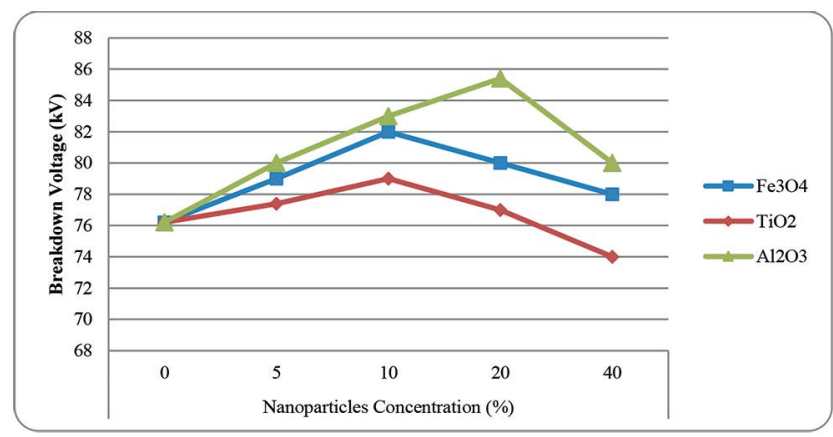

Figure 16. Positive impulse sparking voltage of different nanofluids ${ }^{27}$.

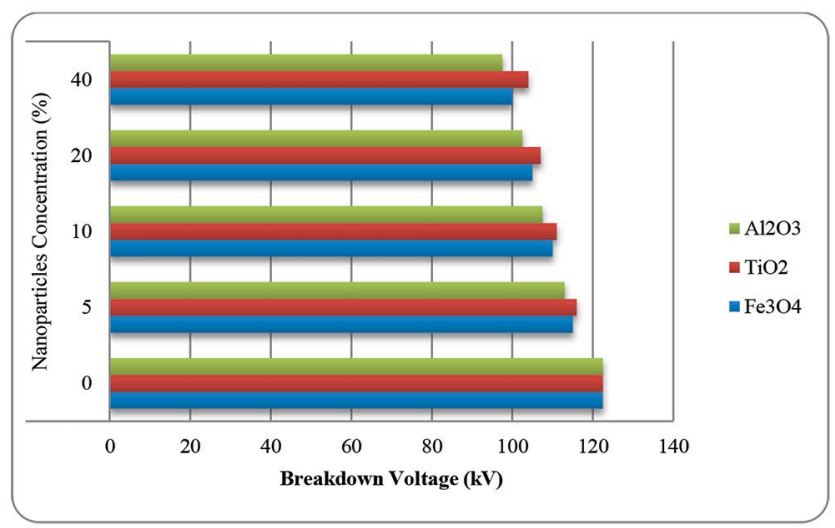

Figure 17. Negative impulse sparking voltage of different nanofluids ${ }^{27}$.

The dielectric strength improves due to the alteration of space charge activity until the critical value of concentration is achieved. The nanoparticles with greater volume in transformer oil can lead to the evolution of the clusters and hence diminish the breakdown voltage.

The 11.2\% augmentation in impulse strength of $\mathrm{Fe}_{3} \mathrm{O}_{4}$ modified transformer oil was examined by Yang et al. . $^{32}$. The electrons crossing the gap at fast velocity were trapped and turned into slow running electrons that hinder the ionization process and thus improve the impulse strength.

The inspection on electrical strength of $h-B N$ nanoparticle based vegetable nanofluid under application of an artificial lightning impulse as per the methodology of IEC 60897 is reported by $\frac{52}{2}$. Figure 18 shows the results obtained for impulse BDV at positive and negative polarity of applied impulse wave for different densities of nanoparticles.

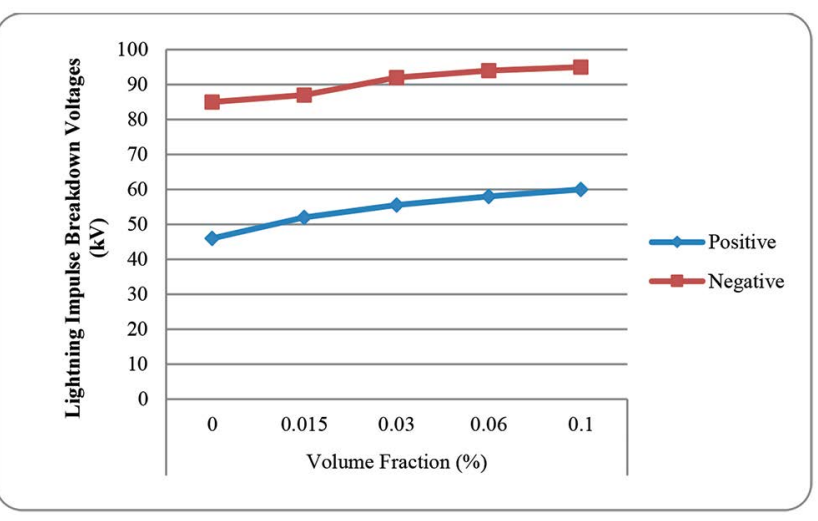

Figure 18. Positive and Negative Impulse BDV for vegetable oil based nanofluid ${ }^{52}$.

The impulse breakdown voltage strength of pure vegetable oil can be improved by dispersing the nanoparticles in the host fluid. They noticed $22.0 \%$ and $28.8 \%$ improvement in positive and negative impulse values respectively. Furthermore, the value of negative impulse was examined lower than the value obtained during application of positive impulse. The difference observed due to reversal of polarity was explained on basis of space charge behavior.

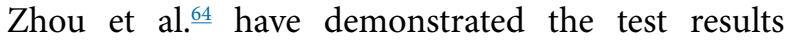
of conducted impulse voltage test on transformer oil modified by suspending $\mathrm{Fe}_{3} \mathrm{O}_{4}, \mathrm{TiO}_{2}$ and $\mathrm{Al}_{2} \mathrm{O}_{3}$ nanoparticles. The dispersed nano-structured particles can modify the beginning and transmission processes of positive streamers in transformer oil.

In $\underline{65}$ have conducted an experiment to examine the alteration occurred in impulse dielectric strength when both mineral oil and natural esters modified by nanoparticles. The modification to the host fluids achieved by dispersing silica nanoparticles during the experimentation. The $30 \%$ augmentation achieved due to the hydrophilic property of silica nanoparticles, which has tendency to absorb the water to alter the degree of 
polarization for preventing the fast ionization of liquid dielectric.

The dielectric capacity at applied impulse voltage for transformer oil modified by nanocrystalline $\mathrm{Mn}_{0.2} \mathrm{Ni}_{0.8} \mathrm{Fe}_{2} \mathrm{O}_{4}$ nanoparticles has been discussed by ${ }^{66}$. The high voltage impulse test was conducted by concentrating the nanoparticles in host oil at weight of $0.02 \mathrm{~g} / 1,0.04 \mathrm{~g} / \mathrm{l}$ and $0.06 \mathrm{~g} / 1$ respectively. The results showed $42.3 \%$ of augmentation in impulse strength when nanoparticles were dispersed at weight of $0.04 \mathrm{~g} / \mathrm{l}$. The negative results were noticed when the concentration of the particles was more than the optimum value.

The experimentation to evaluate the impulse strength (with positive and negative polarity) of pure oil based magnetic nanofluid as a function of volume portion, dimension of nanoparticles and diverse gap lengths was conducted by ${ }^{67}$.

Figures 19, 20 and 21 show the results of positive and negative impulse BDV value obtained by loading multiple nanoparticles in transformer oil by considering volume portion, size of nanoparticles and gap span between two electrodes ${ }^{67}$.

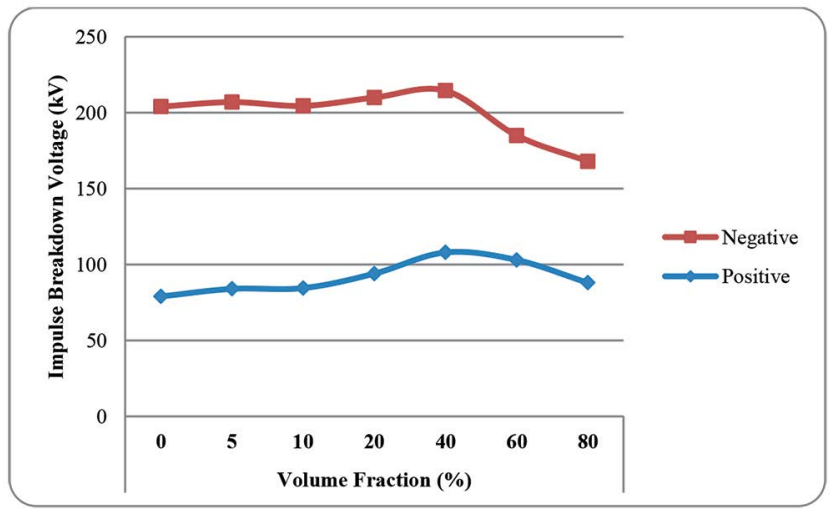

Figure 19. Flashing potential as a function of volume percentage $^{67}$.

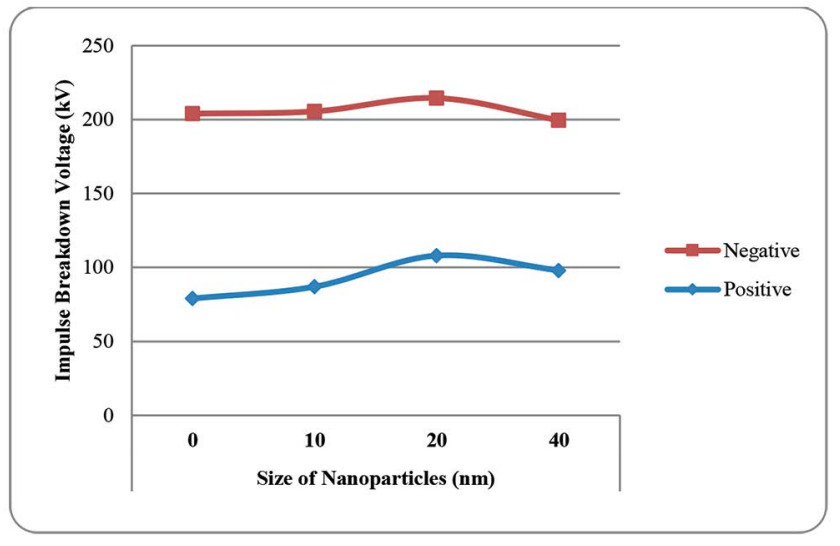

Figure 20. Impulse sparking potential as a function of nanoparticle's size ${ }^{67}$.

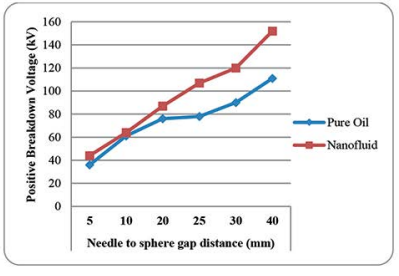

(a) (b)

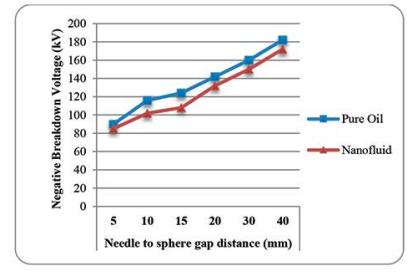

Figure 21. Impulse breakdown voltage at different gap span67. (a) With positive polarity (b) With negative polarity.

Investigation results have depicted 0.4 and $20 \mathrm{~nm}$ values as optimum concentration and size for nanoparticles respectively to obtain augmentation in electrical stress holding capacity of insulation under positively applied short duration voltage of high magnitude as compared to carrier oil. Contradictory, an application of negative impulse voltage shows worse performance as compared to base fluid.

$\mathrm{In}^{\underline{68}}$ have prepared nanofluid by spreading $\mathrm{ZnO}$ nanoparticles in Refined Sunflower Oil (RSFO) type natural esters to investigate impulse dielectric strength. They evaluated $28.95 \%$ and $20.04 \%$ extension in impulse strength as compared to carrier fluid. The reduction in electrical conductivity due to slowing down the transmission velocity of streamer enhances the dielectric strength.

Table 6 represents the list of the researchers who have conducted the experiments to evaluate the impulse strength of nanofluids.

Table 6. List of researchers conducted impulse voltage test

\begin{tabular}{|c|c|c|c|}
\hline Ref & Author (s) & Base material & Nanoparticle (s) \\
\hline 35 & Li et al. & Vegetable oil & $\mathrm{Fe}_{3} \mathrm{O}_{4}$ \\
\hline 39 & Sima et al. & Kelamayi\# 25 TO & $\mathrm{Fe}_{3} \mathrm{O}_{4}, \mathrm{TiO}_{2}, \mathrm{Al}_{2} \mathrm{O}_{3}$ \\
\hline 69 & Rafiq et al. & Kelamayi\# 25 TO & Alumina \\
\hline 70 & Du et al. & Vegetable oil & $\mathrm{Fe}_{3} \mathrm{O}_{4}$ \\
\hline 71 & $\begin{array}{c}\text { Nazari et } \\
\text { al. }\end{array}$ & $\begin{array}{c}\text { NYTRO LIBRA } \\
\text { TO }\end{array}$ & $\mathrm{Fe}_{3} \mathrm{O}_{4}$ \\
\hline 72 & $\begin{array}{c}\text { Y.Z.Lv et } \\
\text { al. }\end{array}$ & $\begin{array}{c}\text { Impregnated } \\
\text { Press board }\end{array}$ & $\mathrm{TiO}_{2}$ \\
\hline 73 & $\begin{array}{c}\text { Mu-tian } \\
\text { et al. }\end{array}$ & Kelamayi\# 25 TO & $\mathrm{TiO}_{2}$ \\
\hline 74 & Du et al. & Kelamayi\# 25 TO & $\mathrm{TiO}_{2}$ \\
\hline
\end{tabular}




\subsection{Partial Discharge Inception Voltage (PDIV)}

PDIV characteristics before and after aging of pure oil and equivalent nanofluids was studied by ${ }^{22}$. Before aging, the ferrofluid does not modify the PDIV characteristic significantly as compared to tin oxide and $\mathrm{SiO}_{2}$ based nanofluids. For both AC and DC voltages, silicone dioxide based nanofluids shows the improvement. Additionally, compared to the mineral oil and other nanofluids, aged $\mathrm{SiO}_{2}$ shows the better response. The enhancement shown by silicon dioxide based nanofluid is due to its hydrophilic property.

The partial discharge test to examine the facts of nanoparticles on inception of partial discharges had been executed ${ }^{23}$. Table 7 shows the results obtained after performing partial discharge test. The positive results are obtained for partial discharge inception voltage and discharge magnitude. The addition of semiconducting nanoparticles diminishes the probabilities of incidence of partial discharge initiation.

Table 7. PDIV value for $\mathrm{TiO}_{2}$ based nanofluid $\mathrm{d}^{23}$

\begin{tabular}{|c|c|c|c|c|}
\hline Sample & $\begin{array}{c}\text { Mean } \\
\text { PDIV } \\
(\mathrm{kV})\end{array}$ & $\begin{array}{c}\text { SD } \\
(\mathrm{kV})\end{array}$ & $\begin{array}{c}63.2 \% \\
\text { Probability } \\
\text { PDIV }(\mathrm{kV})\end{array}$ & $\begin{array}{c}5 \% \text { Probability } \\
\text { PDIV (kV) }\end{array}$ \\
\hline MO & 30.6 & 2.7 & 31.7 & 25.0 \\
\hline NF & 33.1 & 1.8 & 33.8 & 29.5 \\
\hline
\end{tabular}

Thetrapping and de-trapping nature of semiconducting nanoparticles improves the PDIV characteristics for both new and aged $\mathrm{TiO}_{2}$ based nanofluid ${ }^{24}$. The $1.12 \%$ enhancement is achieved as compared to mineral oil.

Jin et al. $\underline{\underline{28}}$ has studied the incomplete discharge performance of fluid produced by disseminating $0.01 \%$ of fullerene and silica nanoparticles. Under positive DC voltage, twenty percent improvement was noticed in PDIV value for silica based transformer oil compared to its pure state. Furthermore, the discharge magnitudes for silica and fullerene nanofluid were scaled down to $63 \%$ and 33\% respectively. The reaction of the nanoparticle's surface with acid in mineral oil leads less effect on partial discharge behavior.

In $\frac{75}{}$ have developed the magnetite-based nanofluid to investigate partial discharge inception voltage characteristic. The lower concentration of nanoparticles could enhance PDIV characteristic as compared to carrier oil and at higher concentration. The conductive nanoparticles attract the electrons emitted due to ionization and turns into negative ions to quench the avalanche.

In $\frac{76}{6}$ have made an effort to develop the natural ester based nanofluid by dispersing $\mathrm{TiO}_{2}$ nanoparticles for examining the partial discharge inception performance under applied ac voltages. The negligible enhancement in PDIV of nanofluid has noticed.

In ${ }^{77}$ have made an effort to examine the PDIV for aged nanofluid prepared by dispersing the semiconducting nanoparticles at low and high moisture content. The aging to the fluid was achieved by heating the oil at $130^{\circ} \mathrm{C}$ for 6 days. The Figure 22 shows the results obtained for the voltage magnitude at which the partial discharge activity begins. Because of dispersion of semiconducting nanoparticles, the rate of moisture opposition and antiageing properties of aged pure oil enhances which further giving rise to corona inception voltage.

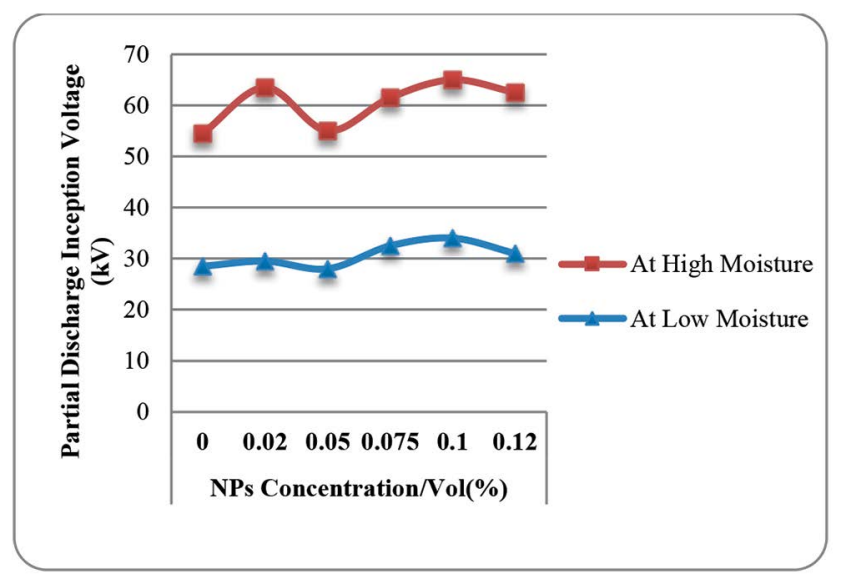

Figure 22. PDIV at low and high moisture for prepared $\mathrm{NF}^{77}$.

Table 8 represents the list of the researchers who have conducted the experiments to evaluate the PD characteristics of nanofluids.

\subsection{Critical Characteristics}

Critical characteristics include the electrical conductivity, permittivity, dissipation factor, resistivity, flash point and fire point. Several researchers have contributed to identify the effect of nanoparticles on such unavoidable parameters. In ${ }^{29}$ have investigated the influence of semi conductive Cadmium Sulfide (CdS) quantum dots on relative permittivity and dissipation factor by preparing the fluid at various concentrations. Figures 23 and 24 
Table 8. List of researchers investigated PD characteristics of NF

\begin{tabular}{|c|c|c|c|}
\hline Ref & Author (s) & Base material & $\begin{array}{c}\text { Nanoparticle } \\
(\mathrm{s})\end{array}$ \\
\hline 41 & Cavallini et al. & Shell Diala D & $\begin{array}{c}\text { Magnetite, GO, } \\
\text { SO }\end{array}$ \\
\hline 63 & Z. You et al. & $\begin{array}{c}\text { Transformer } \\
\text { oil }\end{array}$ & $\mathrm{TiO}_{2}$ \\
\hline 73 & Mu-tian et al. & $\begin{array}{c}\text { Kelamayi\# 25 } \\
\text { TO }\end{array}$ & $\mathrm{TiO}_{2}$ \\
\hline 78 & Y. Du et al. & Mineral Oil & $\mathrm{TiO}_{2}$ \\
\hline 79 & $\begin{array}{c}\text { D. Prasad and S. } \\
\text { Chandrasekar }\end{array}$ & $\begin{array}{c}\text { FR3 TO } \\
\mathrm{SiO}_{2}\end{array}$ \\
\hline 80 & M. Dehkordi & $\begin{array}{c}\text { Transformer } \\
\text { oil }\end{array}$ & $\mathrm{TiO}_{2}$ \\
\hline
\end{tabular}

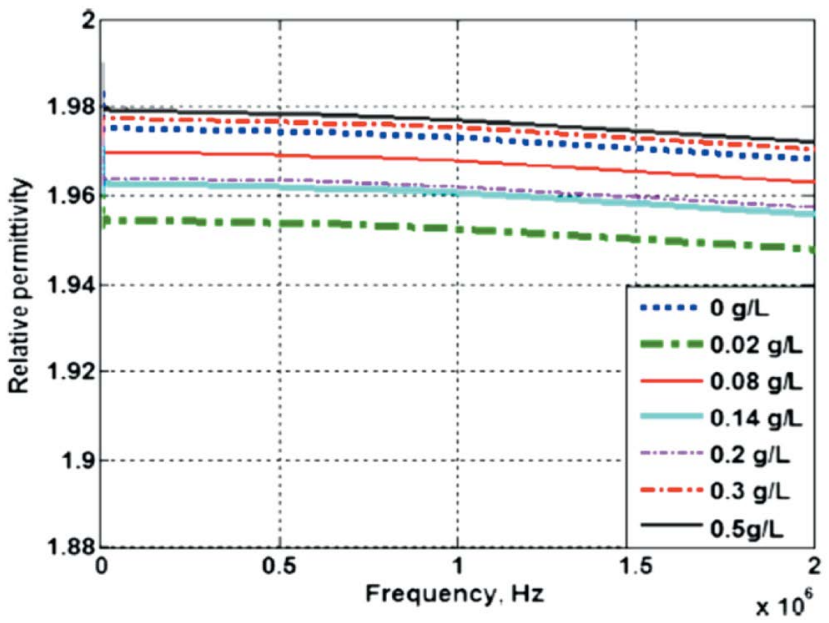

Figure 23. Dielectric constant Vs volume concentration of CdS quantum dots in host oil ${ }^{29}$.

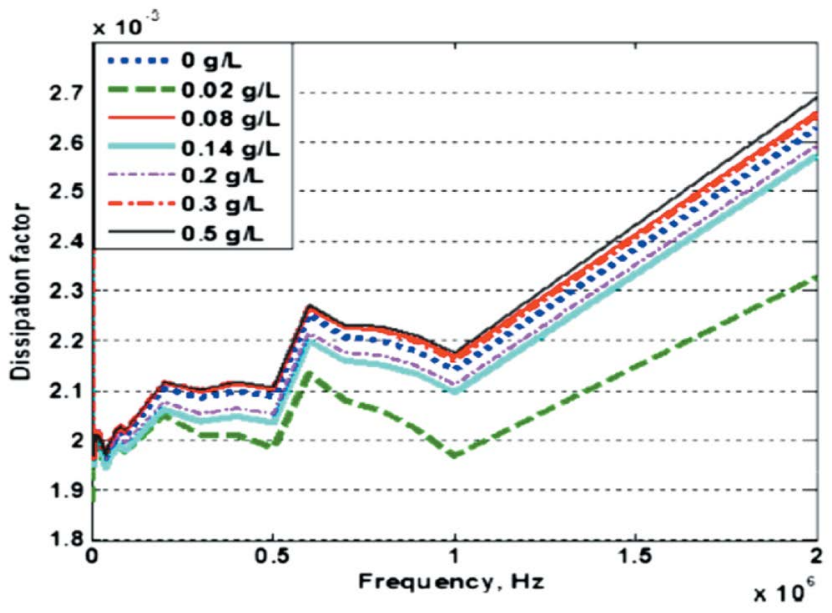

Figure 24. Dissipation factor of modified host oil 29 . shows the effect of nanoparticles' application on dielectric constant and tan delta of modified host oil respectively.

The slight increment in dielectric constant of nanofluid was because of the contribution to the net amount of dipoles in mineral oil. In general, due to the defects/ impurities in the insulations during its development, it always possesses the two different kinds of permittivities i.e. real permittivity and imaginary permittivity.

The electrostatic forces exerted between the electrons and positive ions are greatly influenced by real part of permittivity whereas the dissipation factor/dielectric losses depend on imaginary part of permittivity. At small concentrations of nanoparticles, the real part of permittivity was enhanced but at concentration, more than the optimum value increases the electrical conductivity due to rise in its surface area that leads to increase in imaginary permittivity and hence dielectric losses.

$\operatorname{In}^{30}$ have carried out the research on mixture of $\mathrm{MgMnNi}$ NPs and transformer oil to observe the performance of electrical conductivity at diverse volume percentage of nanoparticles. Figure 25 shows the dependency of electrical conductivity on volume fraction nanoparticles. They observed the linear increase in electrical conductivity with increase in concentrations.

The resistivity and electrical conduction property of transformer oil modified by AGQD nanoparticles as a function of thermal stress was investigated by ${ }^{49}$ and showed in Figures 26, 27 respectively.

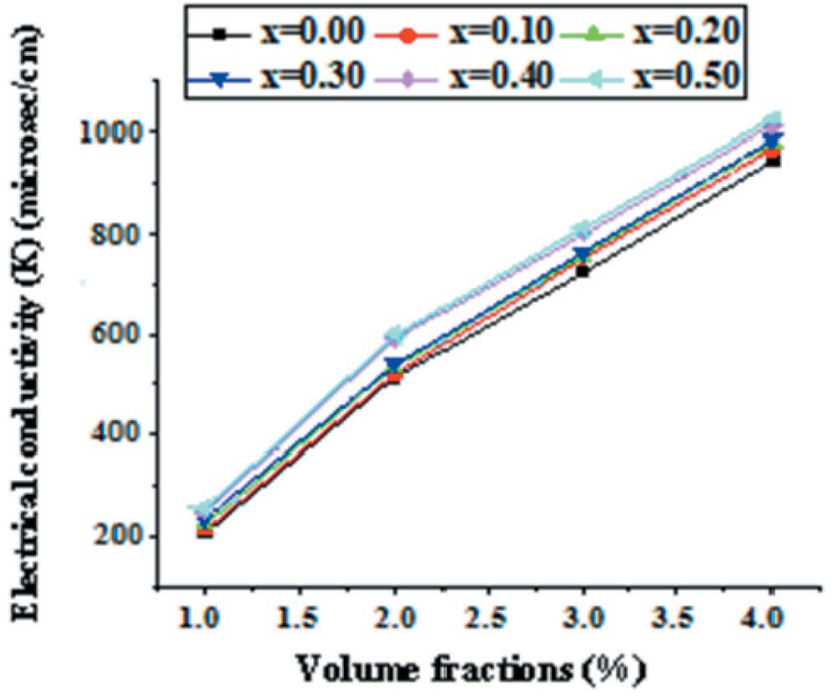

Figure 25. Dependency of electrical conductivity on volume fraction of Nanoparticles ${ }^{30}$. 


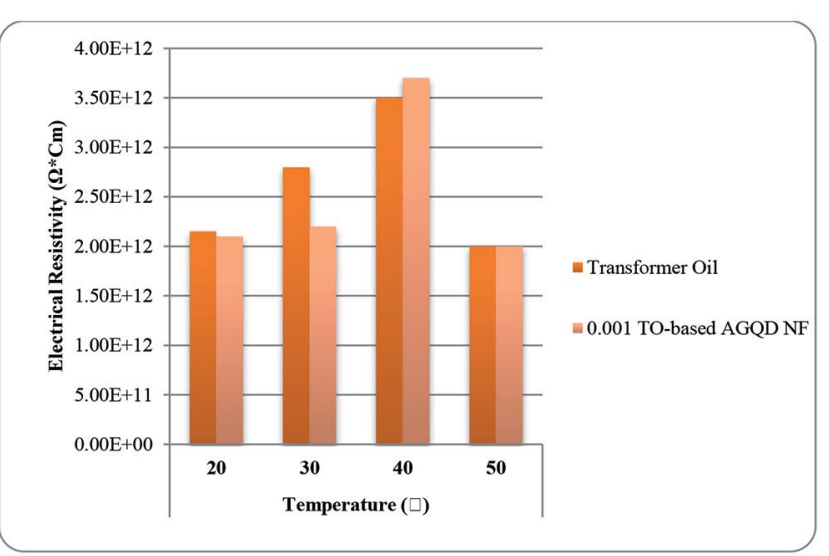

Figure 26. Resistivity of TO based AGQD NF.

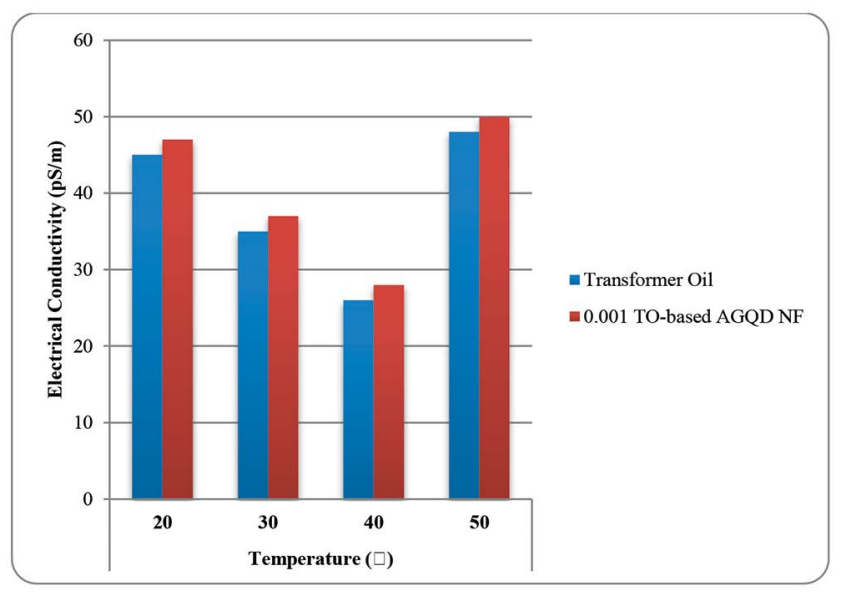

Figure 27. Electrical conductivity of TO based AGQD NF.

Because of inherent electrical transfer ability of dispersed nanoparticles, the electrical resistivity was slightly enhanced but confliction has been observed as a reduction in electrical resistivity when $0.001 \%$ of nanoparticles were loaded. Furthermore, the electrical conductivity was not changed noticeably.

Figure 28 shows the results of dielectric properties

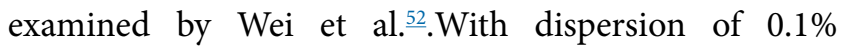
concentration of nanoparticle could enhance the relative permittivity by 3.11 at $25 \%$, resistivity by $63 \%$ and decrease the dielectric losses by $28 \%$ at $25 \%$ and $90 \%$ compared to base oil without nanoparticles.

In $\frac{68}{6}$ have prepared a nanofluid by dispersing $\mathrm{TiO}_{2}$ and $\mathrm{ZnO}$ nanoparticles in dielectric fluid derived from natural esters to investigate critical characteristics such as flash point and fire point.

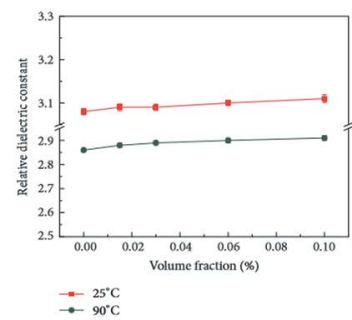

(a)

Figure 28. Critical parameters of nano-oil as a function of volume concentration at $25 \%$ and $90^{\circ} \mathrm{C}{ }^{52}$. (a) Relative Permittivity (b) Resistivity and Tan Delta.

Table 9 represents the list of the researchers who have conducted the experiments to evaluate the critical parameters of nanofluids.

\section{Modification Mechanisms}

The mechanisms by which the nanoparticles can disturb the electrical properties of host oil are still not fully revealed. $\operatorname{In}^{19}$ have proposed a double layer model to certify the strengthening of the electrical insulation properties

Table 9. List of researchers evaluated the critical parameters of NF

\begin{tabular}{|c|c|c|c|c|}
\hline Ref. & Author(s) & Base Fluid & Nanoparticle(s) & Parameter(s) examined \\
\hline 42 & J. Fal et al. & Ethylene glycol & $\mathrm{SC}-\mathrm{TiO}_{2}$ & Electrical Conductivity \&Permittivity \\
\hline 53 & S. Quing et al. & Mineral oil & $\begin{array}{c}\mathrm{SiO}_{2} \text {-Graphene } \\
\text { hybrid }\end{array}$ & Electrical Conductivity \\
\hline 55 & M. Makmud et al. & Natural Ester & $\mathrm{TiO}_{2}, \mathrm{Fe}_{2} \mathrm{O}_{3}$ & Dielectric constant and Dielectric loss \\
\hline 61 & B. Du et al. & Vegetable oil & $\mathrm{BN}$ & $\begin{array}{c}\text { Relative permittivity, Dissipation factor \& } \\
\text { Electrical Conductivity }\end{array}$ \\
\hline 62 & B.Du et al. & Transformer oil & $\mathrm{BN} \mathrm{\&} \mathrm{Fe}_{3} \mathrm{O}_{4}$ & $\begin{array}{c}\text { Relative Permittivity, Dissipation factor \& } \\
\text { Resistivity }\end{array}$ \\
\hline
\end{tabular}




\begin{tabular}{|c|c|c|c|c|}
\hline 70 & B. Du et al. & Vegetable oil & $\mathrm{Fe}_{3} \mathrm{O}_{4}$ & $\begin{array}{l}\text { Relative Permittivity, Dissipation factor \& } \\
\text { Resistivity }\end{array}$ \\
\hline 81 & $\begin{array}{c}\text { Chitra and } \\
\text { Sendhilnathan }\end{array}$ & Transformer oil & $\begin{array}{l}\mathrm{Mg}_{0.40} \mathrm{Mn}_{0.60}- \\
\mathrm{Ni}_{\mathrm{x}} \mathrm{Fe}_{2} \mathrm{O}_{4}\end{array}$ & Electrical Conductivity \\
\hline 82 & $\begin{array}{l}\text { Raymon and } \\
\text { Karthik }\end{array}$ & Transformer oil & $\begin{array}{l}\text { Activated } \\
\text { Bentonite }\end{array}$ & Flash point and Fire point \\
\hline 83 & D. Jasper et al. & Silicone oil & $\mathrm{SiO}_{2}, \mathrm{ZnO}$ & Flash point and Fire point \\
\hline 84 & A. Raymon et al. & $\begin{array}{c}\text { Coconut oil, Cottonseed oil, } \\
\text { Ricebran oil, Rapeseed oil, } \\
\text { Soybean oil and Sunflower } \\
\text { oil }\end{array}$ & $\begin{array}{c}\mathrm{Al}_{2} \mathrm{O}_{3}, \mathrm{TiO}_{2}, \mathrm{Cds} \\
\mathrm{Fe}_{2} \mathrm{O}_{3}\end{array}$ & Flash point and Fire point \\
\hline 85 & M. Emara et al. & Mineral oil & $\mathrm{TiO}_{2}$ & Dielectric constant and Dissipation factor \\
\hline 86 & $\begin{array}{l}\text { D. Zmarzly and D. } \\
\text { Dobry }\end{array}$ & Mineral oil & $\mathrm{C}_{60}$ Fullerenes & Permittivity, Tan Delta \& Resistivity \\
\hline 87 & M. Dong et al. & Transformer oil & AlN & Electrical Conductivity \\
\hline 88 & J. Miao et al. & Transformer oil & $\mathrm{ZnO}$ & Relative Permittivity \\
\hline
\end{tabular}

of nanofluids improved by surfactant. The surfactant plays a dynamic role in the stabilization of nanoparticles through two different mechanisms: (1) Steric stabilization and (2) Electrostatic stabilization. Steric stabilization was attained by capping the active surface of nanoparticles with surfactant to the degree that reduces surface activity and prevents agglomeration. Figure 29 shows the steric stabilization and role of surfactant.

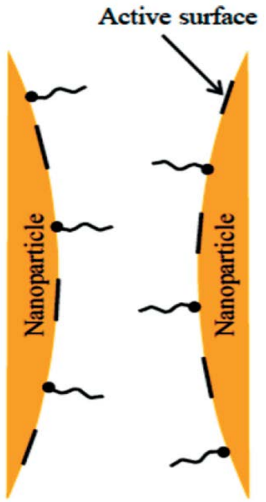

(a)

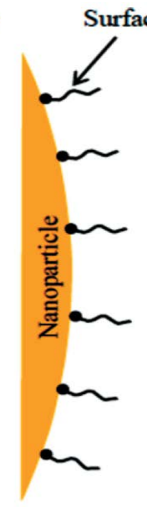

(b)

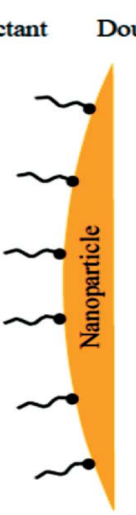

b)

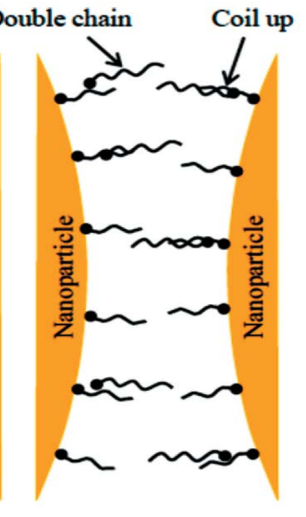

(c)
Figure 29. Steric stabilization and role of surfactant: (a) low coverage, (b) Full coverage and (c) Excess amount of surfactant ${ }^{19}$.

If the surfactant is covered with low surfactant, the agglomeration of nanoparticles may occur due to insufficient coating which do not cover the particle fully and hence unable to oppose the wan der waal attraction force which tend to reduce the electrical performance of the nanofluids developed for insulation purpose.
On the other hand, with excess amount of surfactant, adsorption sites on nanoparticle surface will be rare. Hence, surfactant will form a double chain around the surface of nanoparticles, resulting in a reverse effect

The electrostatic stabilization is achieved by charging the particles with the same polarity as shown in Figure 30. In this model a layer of oppositely charged ions, called counter ions or coions, counter balances the charges. The coions exist in two distinct layers. The inner layer stuck to the nanoparticle surface called stern layer, which is characterized by high concentration of coions. The other layer extends from the stern layer to the zero charging region of the oil called the diffuse layer.

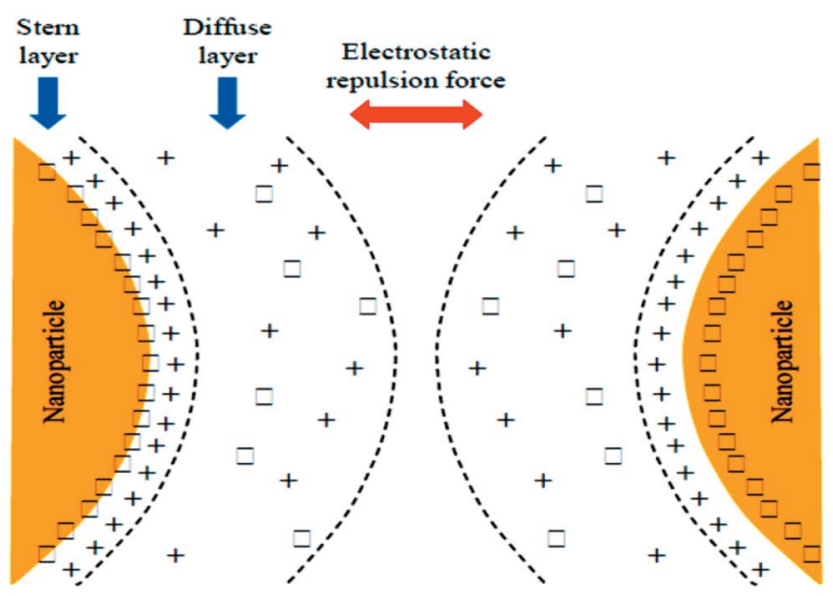

Figure 30. Electrostatic stabilization and double layer $\operatorname{model}^{19}$. 
$\operatorname{In}^{26}$ have proposed a mechanism to explain the significant change happened in the streamer transmission due to modification in space charge scattering when $\mathrm{TiO}_{2}$ nanoparticles were dispersed in transformer oil.

The ionization probability reduces due to trapping and de-trapping charge transportation in oil as the $\mathrm{TiO}_{2}$ nanoparticles upturns the shallow trap density in nanofluid and thus builds up the negative ions which modifies the electric field at the head of the streamer transmitting towards the ground electrode.

For positive polarity as shown in Figure 31(a), the electric field at the streamer tip is enhanced while at ground electrode it is weakened. Thus, it is tough for positive streamers in nanofluid to expand which results in increase in positive breakdown voltage. Contradictory, for negative polarity as shown in Figure 31(b), the electric field at the negative streamer tip is weakened as compared to ground electrode. As an effect, the streamers will propagate to the ground electrode at high velocity.

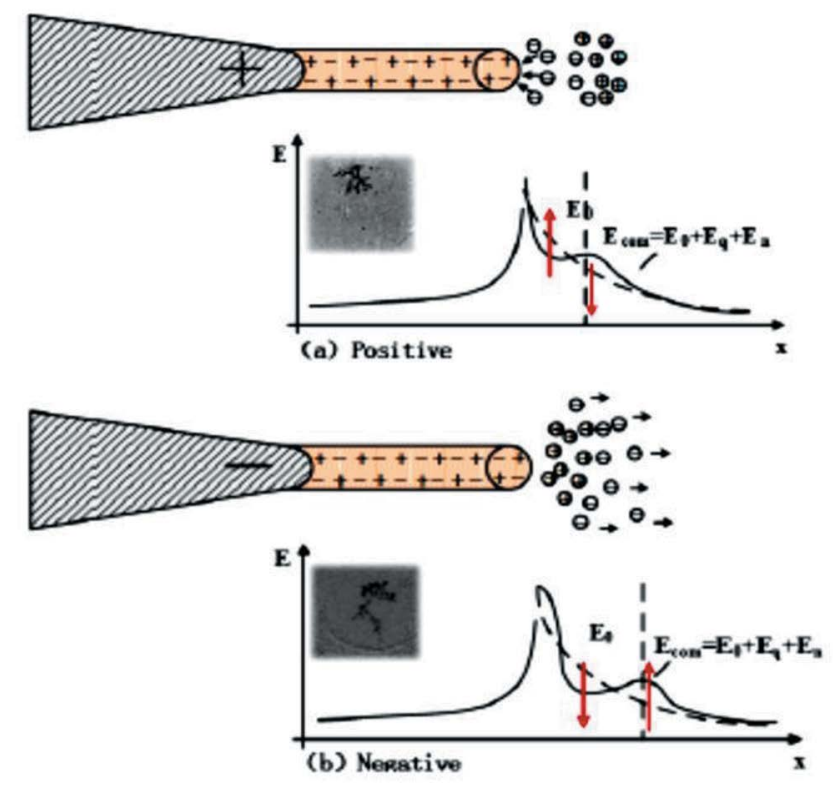

Figure 31. Distribution of electric field in nanofluid ${ }^{26}$.

$\mathrm{In}^{29}$ proposed that the quantum dots of smaller size can increases the surface area and allows more trapping to the electrons that helps in improvement of dielectric properties. The presence of appropriate content of surfactant can improve the morphology of nanoparticles and hinder the physical agglomeration of them $\frac{31}{1}-\underline{32}$ projected a model based on space charge inhibition on improvement of dielectric strength. Figure
32 shows the space charge diffusion characteristics in modified transformer oil. The adsorption of free charge by nanoparticles could improve the insulation strength by (1) delaying electron's movement, (2) blocking charge injection in transformer oil, (3) sinking the space charge density and (4) augmenting the uniformity of the electric field.

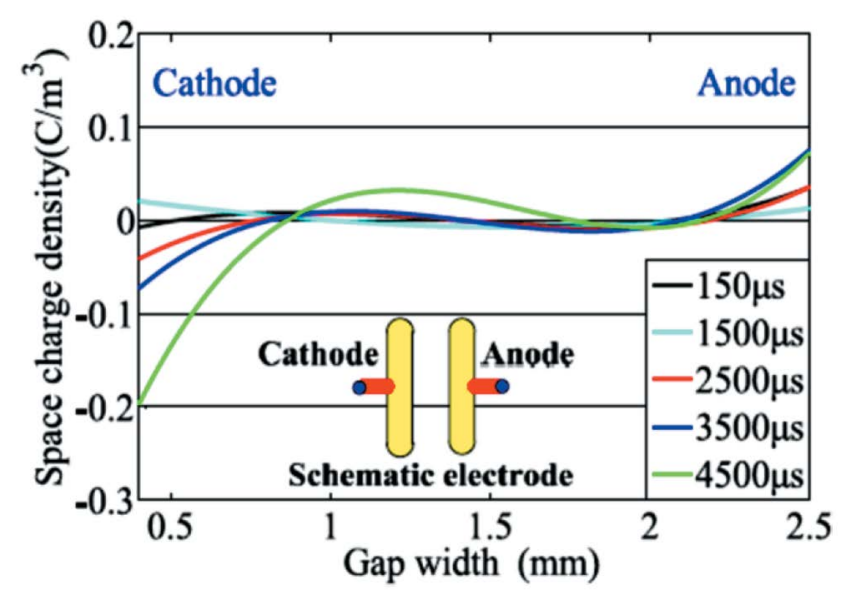

Figure 32. Concentration of space charge in modified transformer oil ${ }^{32}$.

According to the postulation proposed by DerjaguinLandau-Verwey-Overbeek (DLVO), the cumulative reaction between two particles is the mixture of electrostatic repulsion force and van der Waals attraction force ${ }^{19,33}$. When nanoparticles are separated by a distance larger than the combined thickness of their electric double layers, there would be no interaction between the nanoparticles. The repulsion takes place when the nanoparticles moves closer and overlaps the double layer. Stabilization is maintained when the repulsion force becomes equal or exceeds van der Waals attraction force otherwise agglomeration occurs. The addition of surfactant will increase the number of coions and hence increases in electrostatic repulsion force which in turn enhance the dielectric property of nanofluid.

$\operatorname{In}^{47}$ have analyzed the alteration achieved in dielectric possessions of transformer oil by dissolving discrete and manifold nanoparticles and discussed the mechanism of modification achieved in dielectric properties. The addition of multiple nanoparticles could improve the polarization and improves the rate of electron absorption as compared to individual nanoparticles.

Most of the researchers have also proposed the enhancement mechanisms in dielectric properties on the 
ground of the relaxation time constant and polarization characteristics ${ }^{27}$.

\section{Conclusion}

Emerging nanofluid research brings the ample opportunities to the researchers in developing the nanoparticle based high voltage electrical insulation fluids with superior properties as equaled to present mineral oil. The survey reported in this article discusses the efforts placed in past years with an intention to investigate the performance of nanofluid based transformer oil under heavy electrical stresses. Although, the superiority of the nanoparticle based transformer oil has been confirmed, still, many facts i.e. the mechanism of ionization that could be applicable equally to the variety of the nanoparticle based insulation fluid, performance of nanofluids under magnetic field, performance of nanofluids under contaminated state, selection of nanoparticles for providing both insulation and heat transfer performance when they intended to disperse in transformer oil, dissipation factor, arc suppression characteristics etc. need to be discovered. In-depth experimentation and multidisciplinary research is required for better understanding of mechanisms and behavior of nanofluids to resolve the prevailing challenges.

\section{References}

1. Electrical power equipment maintenance and testing. [Internet]. [cited 1998]. Available from: https://www. academia.edu/33236618/Electrical_Power_Equipment_ Maintenance_and_Testing_-_2nd_Edition.

2. Chiesa M, Sarit K. Experimental investigation of dielectric and cooling performance of colloidal suspensions in insulating media. Colloids and Surfaces A: Physicochemical and Engineering Aspects. 2009; 335(1-3):88-97. https:// doi.org/10.1016/j.colsurfa.2008.10.044

3. Rafiq M, Yuzhen LV, Li C. A review on properties, opportunities, and challenges of transformer oil-based nanofluids. Journal of Nanomaterials. 2016:1-23. https:// doi.org/10.1155/2016/8371560

4. Liu R, Pettersson L, Auletta T, Hjortstam O. Fundamental research on the application of nano dielectrics to transformers. IEEE Annual Report Conference on Electrical Insulation and Dielectric Phenomena; 2011. p. 423-7. https://doi.org/10.1109/CEIDP.2011.6232685
5. Fofana I. 50 Years in the development of insulating liquids. IEEE Insulation Magazine. 2013; 29(5):13-25. https://doi. org/10.1109/MEI.2013.6585853

6. Singh M, Lal K. Experimental study on thermal conductivity and viscosity of Al2O3-nanotransformer oil. International Journal on Theoretical and Applied Research in Mechanical Engineering. 2013; 2(3):125-30.

7. LiD, Xie W, Fang W. Preparation and properties of copper-oilbased nanofluids. Nanoscale Research Letter; 2011. p. 1-12. https://doi.org/10.1186/1556-276X-6-373. PMid:21711900, PMCid:PMC3211464

8. Jin H, Andritsch T, Tsekmes I, Kochetov R, Morshuis P, Smit J. Thermal Conductivity of Fullerene and TiO2 Nanofluids. IEEE Annual Report Conference on Electrical Insulation and Dielectric Phenomena; 2013. p. 711-14. https://doi. org/10.1109/CEIDP.2013.6748177. PMCid:PMC3718302

9. Cheng H, Zhang P, Zhang Q, Wu J, Dai Y, Hu W, Norman M. Effects of surface modification on the stability of suspension and thermalconductivityenhancementofcompositeFenanofluids. IEEE Transactions on Magnetics. 2014; 50(11):1-12. https://doi.org/10.1109/TMAG.2014.2330629

10. Du B, Li X, Xiao M. High thermal conductivity transformer oil filled with BN nanoparticles. IEEE Transactions on Dielectrics and Electrical Insulation. 2015; 22(2):851-58. https://doi.org/10.1109/TDEI.2015.7076784

11. Contreras J, Rodrrriguez E, Taha-Tijeriana J. Nanotechnology applications for electrical transformers - A review. Electrical Power Systems Research. 2017; 143:573-84. https://doi.org/10.1016/j.epsr.2016.10.058

12. Lv Y, Zhou Y, Li C, Wang Q, Qi B. Recent progress in nanofluids based on transformer oil: Preparation and electrical insulation properties. IEEE Insulation Magazine. 2014; 30(5):23-32. https://doi.org/10.1109/MEI.2014.6882597

13. Lv Y, Wang L, Li X, Du Y, Zhou J, Li C. Experimental investigation of breakdown strength of mineral oil-based nanofluids. IEEE International Conference on Dielectric Liquids; 2011. p. 1-10.

14. Karthik R, Sreerenga T, Madavan R. Enhancement of critical characteristics of transformer oil using nanomaterials. Arabian Journal of Science and Engineering. 2013; 38(10):2725-33. https://doi.org/10.1007/s13369-012-0479-8

15. Du B, Li X, Li J. Thermal conductivity and dielectric characteristics of transformer oil filled with $\mathrm{BN}$ and $\mathrm{Fe} 3 \mathrm{O} 4$ nanoparticles. IEEE Transactions on Dielectrics and Electrical Insulation. 2015; 22(5):2530-6. https://doi. org/10.1109/TDEI.2015.005079

16. Huifei J, Thomas A, Ioannis A, Roman K, Peter M, Johan S. Properties of mineral oil based silica nanofluids. IEEE Transactions on Dielectrics and Electrical Insulation. 2014; 21(3):1100-08. https://doi.org/10.1109/ TDEI.2014.6832254 
17. Irwanto A, Suwarno C, Cavallini A, Negri F. Ferrofluid effect in mineral oil: PDIV, streamer, and breakdown voltage. International Conference on High Voltage Engineering and Application; 2014. p. 1-16. https://doi.org/10.1109/ICHVE.2014.7035481

18. Lee J, Kim W. Experimental study on the dielectric breakdown voltage of the insulating oil mixed with magnetic nanoparticles.18th International Vacuum Congress; 2010. p. 1-6.

19. Eman G, Diaa-Eldin A, Reham M, Ahmed M. Dispersion behavior and breakdown strength of transformer oil filled with TiO2 nanoparticles. IEEE Transactions on Dielectrics and Electrical Insulation. 2015; 22(5):2463-72. https://doi. org/10.1109/TDEI.2015.004742

20. Jin H, Peter M, Johan J, Thomas A. The effect of surface treatment of silica nanoparticles on the breakdown strength of mineral oil. International Conference on Liquid Dielectrics; 2014. p. 1-10. https://doi.org/10.1109/ICDL.2014.6893073

21. Purbarun D, Ajay K, Lakshmi S, Arvind P, Sarit K. Superior dielectric breakdown strength of graphene and carbon nanotube infused nano-oils. IEEE Transactions on Dielectrics and Electrical Insulation. 2016; 23(2):943-56. https://doi.org/10.1109/TDEI.2015.005477

22. Karthik R, Negri F, Cavallini A. Influence of ageing on dielectric characteristics of silicone di oxide, tin oxide and ferro nanofluids based mineral oil. 2nd International Conference on Advances in Electrical, Electronics, Information, Communication and Bio-Informatics; 2016. p. 1-10. https://doi.org/10.1109/AEEICB.2016.7538348

23. Yuefan D, Yuzhen L, Chengrong L, Mutian C, Yuxiang Z, Jianquan Z, Xiaoxin L, You Z. Effect of semiconductive nanoparticles on insulating performances of transformer oil. IEEE Transactions on Dielectrics and Electrical Insulation. 2012; 19(3):770-6. https://doi.org/10.1109/TDEI.2012.6215079

24. Rafiq M, Wei W, Kaibo M, You Z, Qi W, Chengrong L, Yuzhen L. Insulating and aging properties of transformer oil-based $\mathrm{TiO} 2$ nanofluids. IEEE Conference on Electrical Insulation and Dielectric Phenomena; 2014. p. 1-15. https://doi.org/10.1109/CEIDP.2014.6995798

25. Kudelcik J, Bury P, Kopcansky P, Timko M. Dielectric breakdown in mineral oil ITO 100 based magnetic fluid. 12th International Conference on Magnetic Fluids; 2010. p. 1-18. https://doi.org/10.1016/j.phpro.2010.11.019

26. Yuzhen L, Yang G, Chengrong L, Wang Q, You Z, Bo Q, Kai $\mathrm{Y}$, Xin C, Jinsha Y. Effect of TiO2 nanoparticles on streamer propagation in transformer oil under lightning impulse voltage. IEEE Transactions on Dielectrics and Electrical Insulation. 2016; 23(4):2110-15. https://doi.org/10.1109/ TDEI.2016.7556485
27. Wang Q, Rafiq M, Yuzhen L, Chengrong L, Kai Y. Preparation of three types of transformer oil-based nanofluids and comparative study on the effect of nanoparticle concentrations on insulating property of transformer oil. Journal of Nanotechnology.; 2015. p. 1-6. https://doi. org/10.1155/2016/5802753

28. Huifei J, Peter M, Armando M, Johan S. Partial discharge behavior of mineral oil based nanofluids. IEEE Transactions on Dielectrics and Electrical Insulation. 2015; 22(5):274753. https://doi.org/10.1109/TDEI.2015.005145

29. Abd-Elhady A, Ibrahim M, Taha T, Izzularab M. Dielectric and thermal properties of transformer oil modified by semiconductive CdS quantum dots. Journal of Electronic Materials. 2016; 45:4755-61. https://doi.org/10.1007/ s11664-016-4745-5

30. Chitra S, Sendhilnathan S. Experimental investigations on dielectric fluids behavior in high-power transformers. International Journal of Applied Ceramic Technology. 2016; 13:1096-103. https://doi.org/10.1111/ijac.12520

31. Bin D, Jian L, Bai-Mei W, Zhao-Tao Z. Preparation and breakdown strength of $\mathrm{Fe} 3 \mathrm{O} 4$ nanofluid based on transformer oil. International Conference on High Voltage Engineering and Application; 2012. p. 1-6. https://doi. org/10.1109/ICHVE.2012.6357115

32. Qing Y, Fei Y, Sima W, Zahn M. Space charge inhibition effect of nano-Fe3O4 on improvement of impulse breakdown voltage of transformer oil based on improved Kerr optic measurements. AIP Advances. 2015; 5:1-8. https:// doi.org/10.1063/1.4931947

33. Structure formation in solution: ionic polymers and colloidal particles [Internet]. [cited 2005]. Available from: https://www.springer.com/gp/book/9783540252719.

34. John M, Maria A, Theodore A, Constantine D. Dielectric properties of nanopowder dispersions in paraffin oil. IEEE Transactions on Dielectrics and Electrical Insulation. 2012; 19(5):1502-7. https://doi.org/10.1109/TDEI.2012.6311493

35. Jian L, Zhaotao Z, Ping Z, Stanislaw G. Preparation of a vegetable oil-based nanofluid and investigation of its breakdown and dielectric properties. IEEE Insulation Magazine. 2012; 28(5):43-50. https://doi.org/10.1109/ MEI.2012.6268441

36. Pîslaru-Dănescu L, Alexandru M, Gabriela T, Mihaela M, Jean B, Virgil M. Magnetic nanofluid applications in electrical engineering. IEEE Transactions on Magnetics. 2013; 49(11):5389-497. https://doi.org/10.1109/ TMAG.2013.2271607

37. Yuzhen L, Wei W, Kaibo M, Shengnan Z, You Z, Chengrong L, Wang Q. Nanoparticle effect on dielectric breakdown strength of transformer oil-based nanofluids. IEEE Conference on Electrical Insulation and Dielectric Phenomena; 2013. p. 1-10. 
38. Huifei J, Peter M, Armando M, Thomas A. An investigation into the dynamics of partial discharge propagation in mineral oil based nanofluids. IEEE International Conference on Liquid Dielectrics; 2014. p. 1-12. https://doi.org/10.1109/ ICDL.2014.6893074

39. Sima W, Jian S, Yang Q, Huang S, Cao X. Effects of conductivity and permittivity of nanoparticle on transformer oil insulation performance: Experiment and theory. IEEE Transactions on Dielectrics and Electrical Insulation. 2015; 22(1):380-90. https://doi.org/10.1109/TDEI.2014.004277

40. Raja S, Vishnu S, Niraj K, Vicky P. Enhancement of performance parameters of transformer using nanofluids. International Journal of Scientific Engineering and Technology. 2015; 4(6):383-6. https://doi.org/10.17950/ ijset/v4s6/608

41. Andrea C, Karthik R, Fabrizio N. The effect of magnetite, graphene oxide and silicone oxide nanoparticles on dielectric withstand characteristics of mineraloil.IEEETransactions on Dielectrics and Electrical Insulation. 2015; 22(5):2592-600. https://doi.org/10.1109/TDEI.2015.005016

42. Jacek F, Adriana B, Khrystyna B, Yaroslav B, Marian C, Izabela Z, Kamil S, Józef C, Gaweł Z. Experimental investigation of electrical conductivity and permittivity of SC-TiO2-EG nanofluids. Nanoscale Research Letter; 2016. p. $1-5$.

43. Usman M, Hafiz M. Thermal conductivity of hybrid nanofluids: A critical review. International Journal of Heat and Mass Transfer; 2018. p. 211-34. https://doi.org/10.1016/j. ijheatmasstransfer.2018.05.021

44. Dielectric strength and thermal conductivity of mineral oil based nanofluids [Internet]. [cited 2015]. Available from: http://citeseerx.ist.psu.edu/viewdoc/download?doi=10.1.1. 1003.3415\&rep $=$ rep1\&type $=$ pdf.

45. Sadegh A, Amin J. Tungsten (III) oxide (WO3) - Silver/ transformer oil hybrid nanofluid: Preparation, stability, thermal conductivity and dielectric strength. Alexandria Engineering Journal. 2018; 57(1):169-74. https://doi. org/10.1016/j.aej.2016.11.003

46. Subelia B, Patrick N, Bernard B. Physicochemical properties of oil-based nanofluids containing hybrid structures of silver nanoparticles supported on silica. Industrial and Engineering Chemistry Research. 2011; 50(6):3071-7 https://doi.org/10.1021/ie101088x

47. Ahmed T, Marw A, Salma S. Investigation on enhancing breakdown voltages of transformer oil nanofluids using multi-nanoparticles technique. IET Generation, Transmission and Distribution. 2018; 12(5):1171-76. https://doi.org/10.1049/iet-gtd.2017.1183

48. Zakaria I, Ahmad M, Arief Y, Awang N, Ahmad N. Characteristics of mineral oil-based nanofluids for power transformer application. International Journal of Electrical and Computer Engineering. 2017; 7(3):1530-7. https://doi. org/10.11591/ijece.v7i3.pp1530-1537

49. Ahmad A, Mehdi S, Goodarz A, Shaifulazuar R. Transformer oil-based graphene quantum dots nanofluid as a new generation of highly conductive and stable coolant. International Communications in Heat and Mass Transfer. 2017; 83:40-7. https://doi.org/10.1016/j.icheatmasstransfer.2017.03.011

50. Ming D, Jianshuo D, Yang L, Jiacheng X, Ming R, Zhimin D. Insight into the dielectric response of transformer-oil based nanofluids. AIP Advances. 2017; 7(2):1-7. https:// doi.org/10.1063/1.4977481

51. Olmo C, Fernandez I, Ortiz F, Renedo C, Perez S. Dielectric properties enhancement of vegetal transformer oil with $\mathrm{TiO} 2, \mathrm{CuO}$ and $\mathrm{ZnO}$ nanoparticles. International Conference on Renewable Energies and Power Quality; 2018. p. 1-12.

52. Wei Y, Zhengyong H, Jian L, Liya W, Chenmeng X. Enhanced electrical insulation and heat transfer performance of vegetable oil based nanofluids. Journal of Nanomaterials. 2018:1-12. https://doi.org/10.1155/2018/4504208

53. SooHui Q, Rashmi W, Khalid M, Gupta T, Nabipoor M, Taghi $M$. Thermal conductivity and electrical properties of hybrid $\mathrm{SiO} 2$-graphene napthenic mineral oil nanofluid as potential transformer oil. Materials Research Express. 2017; 4:1-14. https://doi.org/10.1088/2053-1591/aa550e

54. Sandeepkumar M, Vasu V, Venugopal A. Investigation of thermal conductivity and rheological properties of vegetable oil based hybrid nanofluids containing $\mathrm{Cu}-\mathrm{Zn}$ hybrid nanoparticles. Experimental Heat Transfer - A Journal of Thermal Energy Generation, Transport, Storage and Conversion; 2016. p. 205-17. https://doi.org/10.1080/0891 6152.2016.1233147

55. Makmud M, Illias H, Chee C, Sarjadi M. Influence of conductive and semi-conductive nanoparticles on the dielectric response of natural ester-based nanofluid insulation. Energies. 2018; 11(2):1-12. https://doi.org/10.3390/ en 11020333

56. Chitra S, Gayathri V. Physical, chemical properties and applications of transformer oil based ferrofluid/dielectric fluid. American Journal of Materials Synthesis and Processing. 2016; 1(4):47-55.

57. Diaa-Eldin M, Ahmed E, Izzularab M. The role of interfacial zone in dielectric properties of transformer oil-based nanofluids. IEEE Transactions on Dielectrics and Electrical Insulation. 2016; 23(6):3364-72. https://doi.org/10.1109/ TDEI.2016.005697

58. Wittawat S, Amnart S. Investigation on voltage breakdown of natural ester oils based-on $\mathrm{ZnO}$ nanofluids. Advanced Materials Research. 2015; 1119:175-8. https:// doi.org/10.4028/www.scientific.net/AMR.1119.175 
59. Ibrahim M, Abd-Elhady M, Izzulara M. Effect of nanoparticles on Transformer oil breakdown strength: Experiment and Theory. IET Science, Measurement and Technology. 2016; 10(8):839-45. https://doi.org/10.1049/iet-smt.2016.0104

60. Peppas G, Bakandritsos A, Charalampakos V, Pyrgioti E, Jiri T, Radek Z, Gonos L. Ultrastable natural ester based nanofluids for high voltage insulation applications. ACS Applied Materials and Interfaces; 2016. p. 1-30. https://doi. org/10.1021/acsami.6b06084. PMid:27581623

61. Du B, Li X, Li J, Tao X. Effects of BN nanoparticles on thermal conductivity and breakdown strength of vegetable oil. 11th International conference on the Properties and Applications of Dielectric Materials; 2015. p. 1-12. https://doi.org/10.1109/ICPADM.2015.7295312. PMCid:PMC4416434

62. Du B, Li X, Li J. Thermal conductivity and dielectric characteristics of transformer oil filled with $\mathrm{BN}$ and $\mathrm{Fe} 3 \mathrm{O} 4$ nanoparticles. IEEE Transactions on Dielectrics and Electrical Insulation. 2015; 22(5):2530-6. https://doi. org/10.1109/TDEI.2015.005079

63. Zhou Y, Yu-xiang Z, Mu-tian C, Sheng-nan Z, Yue-fan D, Yu-zhen L, Chengrong L, Tong L. Effect of nanoparticles on electrical characteristics of transformer oil-based nanofluids impregnated pressboard. IEEE International Symposium on Electrical Insulation; 2012. p. 1-6. https://doi.org/10.1109/ ELINSL.2012.6251552. PMCid:PMC3440236

64. Zhou Y, Sanyi S, Jie L, Zigui O, Yuzhen L, Chengrong L, $\mathrm{Wu} \mathrm{L}$. The effects of shallow traps on the positive streamer electrodynamics in transformer oil based nanofluids. Journal of Physics D: Applied Physics. 2018; 51(10):1-10. https://doi.org/10.1088/1361-6463/aaab2a

65. Mudang T, Dayal S, Anukumar D, Saibal C. Experimental investigation of transformer oil based nanofluids for applications in distribution transformers. 3rd International Conference on Condition Assessment Techniques in Electrical Systems; 2017. p. 1-10.

66. Hessien M, Sabiha N, Sherif G, Alahmadi A. Enhancement of dielectric characteristics of transformer oils with nanoparticles. International Journal of Applied Engineering Research. 2017; 12(24):15668-73.

67. Yuzhen L, Rafiq M, Chengrong L, Bingliang S. Study of dielectric breakdown performance of transformer oil based magnetic nanofluids. Energies. 2017; 10(7):1-21. https:// doi.org/10.3390/en10071025

68. Srinivasan M, Raguparthy U, Sindhuja K. Raymon A. Investigation and performance analysis of nanoparticles and antioxidants based natural ester. International Journal of Advanced Engineering Technology. 2016; 7(2):1000-7.

69. Rafiq M, Chengrong L, Idris K, Zhifeng H, Yuzhen L, Kai Y. Preparation and breakdown properties of mineral oil based alumina nanofluids. International Conference on Emerging
Technologies; 2015. p. 1-10. https://doi.org/10.1109/ ICET.2015.7389175

70. Bin D, Jian L, Wang F, Wei Y, Yao S. Influence of monodisperse $\mathrm{Fe} 3 \mathrm{O} 4$ nanoparticle size on electrical properties of vegetable oil-based nanofluids. Journal of Nanomaterials; 2015. p. 1-9. https://doi.org/10.1155/2015/560352

71. Nazari M, Rasoulifard M, Hosseini H. Dielectric breakdown strength of magnetic nanofluid based on insulation oil after impulse test. Journal of Magnetism and Magnetic Materials. 2016; 399:1-4. https://doi.org/10.1016/j.jmmm.2015.09.022

72. Lv Y, Zhou Y, Li C, Ma K, Wang Q, Wang W, Zhang S, Jin $Z$. Nanoparticle effects on creeping flashover characteristics of oil/pressboard interface. IEEE Transactions on Dielectrics and Electrical Insulation. 2014; 21(2):556-62. https://doi.org/10.1109/TDEI.2013.004151

73. Mu-tian C, Yue-fan D, Yu-zhen L, Jian-quan Z, Xiao-xin L, Cheng-rong L. Effect of nanoparticles on the dielectric strength of aged transformer oil. Annual Report Conference on Electrical Insulation and Dielectric Phenomena; 2011. p. 1-10. https://doi.org/10.1109/CEIDP.2011.6232744

74. Yuefan D, Yuzhen L, Chengrong L, Mutian C, Jianquan Z, Xiaoxin L, You Z, Tu Y. Effect of electron shallow trap on breakdown performance of transformer oil-based nanofluids. Journal of Applied Physics. 2011; 110(10):1-4.

75. Karthik R, Cavallini A, Azcarraga C. Investigations on the effect of nanoparticles in mineral oil. IEEE conference on Electrical Insulation and Dielectric Phenomena; 2014. p. 1-14. https://doi.org/10.1109/CEIDP.2014.6995885

76. Zhong Y, Lv Y, Li C, Du Y, Chen M, Zhang S, Zhou Y, Chen L. Insulating properties and charge characteristics of natural ester fluid modified by $\mathrm{TiO} 2$ semiconductive nanoparticles. IEEE Transactions on Dielectrics and Electrical Insulation. 2013; 20(1):135-40. https://doi.org/10.1109/ TDEI.2013.6451351

77. Lv Y, Du Y, Zhou J, Li X, Chen M, Li C, Wang G. Nanoparticle effect on electrical properties of aged mineral oil based nanofluid. Cigre Session; 2012. p. 1-6.

78. Du Y, Lv Y, Zhou J, Chen M, Li Z, Li C. Effect of ageing on insulating property of mineral oil-based TIO2 nanofluids. IEEE International Conference on Dielectric Liquids; 2011. p. $1-10$.

79. Prasad D, Chandrasekar S. Effect of Nano-SiO2 particles on partial discharge signal characteristics of FR3 transformer oil. Journal of Advances in Chemistry. 2017; 13(5):1-10. https://doi.org/10.24297/jac.v13i0.5687

80. Dielectric behavior of transformer oil when contaminated and/or fortified with nanoparticles [Internet]. [cited 2014]. Available from: https://constellation.uqac.ca/3036/1/ FarzanehDehkordi_uqac_0862N_10090.pdf.

81. Chitra S, Sendhilnathan S. Experimental Investigations on Dielectric fluids Behavior in High-power Transformers. 
International Journal of Applied Ceramic Technology. 2016; 13(6):1-8. https://doi.org/10.1111/ijac.12520

82. Raymon A, Karthik R. Reclaiming aged transformer oil with activated bentonite and enhancing reclaimed and fresh transformer oils with antioxidants. IEEE Transactions on Dielectric and Electrical Insulation. 2015; 22(1):548-55. https://doi.org/10.1109/TDEI.2014.004094

83. Jasper D, Ravindran M, Madavan R. Enhancement of characteristic performance of silicone oil with semi conductive nano particles. International Conference on Innovations in Information, Embedded and Communication Systems; 2015. p. 1-16. https://doi.org/10.1109/ICIIECS.2015.7192956. PMid:25673672. PMCid:PMC4399565

84. Raymon A, Sakthibalan S, Cinthal C, Subramaniraja R, Yuvaraj M. Enhancement and comparison of nano-ester insulating fluids. IEEE Transactions on Dielectrics and Electrical Insulation. 2016; 23(2):892-900. https://doi. org/10.1109/TDEI.2015.005397
85. Emara M, Mansour D, Azmy A. Dielectric properties of aged mineral oil filled with $\mathrm{TiO} 2$ nanoparticles. 4th International Conference on Electric Power and Energy Conversion Systems. 2015, pp. 1-16. https://doi.org/10.1109/EPECS.2015.7368538

86. Zmarzly D, Dobry D. Analysis of properties of aged mineral oil doped with C60 fullerenes. IEEE Transactions on Dielectrics and Electrical Insulation. 2014; 21(3):1119-26. https://doi.org/10.1109/TDEI.2014.6832256

87. Dong $M$, Shen I, Wang H, Wang HB, Miao J. Investigation on the electrical conductivity of transformer oil-based AlN nanofluid. Journal of Nanomaterials; 2013. p. 1-7. https:// doi.org/10.1155/2013/842963

88. Miao J, Dong M, Ren M, Wu X, Shen L, Wang H. Effect of nanoparticle polarization on relative permittivity of transformer oil-based nanofluids. Journal of Applied Physics. 2013; 113(20):1-5. https://doi.org/10.1063/1.4807297 